\title{
Design of an Improved Hybrid FTC for Faults in Aero-Engine Closed-Loop Control System
}

\author{
Xiaofeng Liu $(\mathbb{D}$, Chenshuang Luo $\mathbb{D}$, and Liuqi Xiong $\mathbb{D}$ \\ School of Transportation Science and Engineering, Beihang University, No. 37 Xueyuan Rd., Haidian District, Beijing 100191, China \\ Correspondence should be addressed to Xiaofeng Liu; liuxf@buaa.edu.cn
}

Received 17 May 2021; Revised 5 July 2021; Accepted 24 August 2021; Published 16 September 2021

Academic Editor: Guillermo Valencia-Palomo

Copyright (C) 2021 Xiaofeng Liu et al. This is an open access article distributed under the Creative Commons Attribution License, which permits unrestricted use, distribution, and reproduction in any medium, provided the original work is properly cited.

\begin{abstract}
Due to the aero-engines in a high temperature, pressure, and spool speed environment, the concurrent faults in actuator/sensor combined with degradation of the aero-engine could arise the problem of closed-loop instability during the flight. For this purpose, an improved hybrid fault-tolerant control (FTC) technique has been studied in this paper to deal with simultaneous failure of actuators and sensors associated with health parameters of the typical components' degradation in aero-engines. The improved hybrid FTC structure combined with the nonlinear thermodynamic component-level (NCL) model-based estimation method merges fault estimation of actuators/sensors and typical components' degradation estimation process into the FTC process. A robust $H_{\infty}$ state feedback controller under the disturbance of simultaneous actuator and sensor faults is designed in the proposed method, together with the switching algorithm serving for the fault estimation and improved hybrid FTC channels. In order to show the feasibility of the proposed method, several semiphysical experiments are engaged to illustrate that the improved hybrid FTC structure can save the tolerant-control time and improve performance of the control system.
\end{abstract}

\section{Introduction}

During the aero-engine operation process, whether there exist failures of actuators and sensors in the closed-loop control system, or performance degradation of the aeroengine components, it may arise the problem of instability of the aero-engine. For these failures are critical to the safety of aero-engines, some methods have been developed in recent decades to reduce the influence of these failures when they occur. Fault-tolerant control (FTC) is one of these methods, and its characteristics ensures that the aero-engine system maintains an acceptable level of performance when the aero-engine close-loop control system failure occurs, such as actuator or sensor fault [1]. And the fault diagnosis technology, as a reliable solution, plays critical role in FTC systems $[2,3]$.

Fault diagnosis-based methods are categorized by model-based and data-driven methods, and the most representative methods include Kalman filtering, fault observers, and artificial intelligence method such as neural network. Fault observer-based method shows great conve- nience and application prospects in the design of FTC system [4-16]. However, the traditional fault observer-based FTC method focuses on a certain type of faults, but the fault situation is very complex in actual situation. Therefore, it needs to be considered in further development of the FTC technology, and FTC allows maintaining current performance close to desirable ones and preserve stability conditions in the presence of actuator/sensor faults with typical components' degradation [17]. There are two main groups of FTC techniques, namely, the active and the passive. The passive FTC techniques are control laws that take into account the fault appearance as a system perturbation. Thus, within certain margins, the control law has inherent fault capabilities, allowing the system to cope with the fault presence. On the other hand, the active FTC techniques adapt the control law using the information given by a Fault Detection and Isolation (FDI) module. With this information, some automatic adjustments in the control loop are done after the fault appearance trying to satisfy the control objectives with minimum performance degradation. The development and characteristics 
of both active and passive approaches have been reviewed by the survey papers appeared in the last decades $[18,19]$. On the other hand, a comparative study between the two approaches can be referred to $[20,21]$.

Typically, in a conventional fault diagnosis, the number of health parameters to be estimated should be less than or equal to the number of the aero-engine output numbers. However, in practice, once the actuator and sensor fail at the same time, the two related fault observers cannot distinguish between these two types of faults, because they affect the aero-engine output together. To deal with the problem, health management system with an on-board engine model (OBEM) has been added to the aero-engine control system to enhance safety and improve engine performance; it can calculate the performance parameters of typical aeroengine components [22-24]. This hybrid estimation structure composed of Kalman filter and OBEM is called a hybrid Kalman filter (HKF) [25-29].

A real-time self-tuning model for aero-engine performance monitoring and fault diagnosis has been proposed in [30-32]. An online tuning aero-engine model (eSTORM) updated by Kalman filter has been presented by $[33,34]$. A set of HKFs has been derived to isolate aero-engine sensor faults in $[35,36]$. A sensor fault-tolerant OBEM tuning structure has been established in $[2,37]$. Among of the previous literatures, the application of HKF in diagnosis analysis of simultaneous actuators and sensors faults have been developed. However, the time-consuming during the diagnosis and control process is still a challenging topic in future study.

In this paper, in order to minimize the influence of simultaneous faults of actuators and sensors, an improved hybrid FTC method is proposed, and there are three modules in its structure. The first one is Fault Detection and Isolation (FDI) module. The other one is FTC combined with fault estimation by an improved hybrid FTC module. In addition, there is channel-switching module utilized to change the process of FDI and FTC. In this structure, the estimation process of faults in actuators and sensors, the performance degradation estimation process in typical aero-engine components, and FTC process are merged into one process, associated with significant reduction of processing time of the FTC.

The following contents contain four sections. Section 2 establishes the thermodynamic nonlinear component-level model of an aero-engine and performs several typical component performance degradation simulations. Section 3 addresses the derivation of the build-up model for the improved hybrid FTC structure and provides the robust $H_{\infty}$ state feedback controller under the disturbance of sensor and actuator faults. In addition, the switching algorithm serving for the FDI and hybrid FTC channels is described in details. Experimental work and its results are conducted and discussed in Section 4 to show the feasibility of the improved hybrid FTC algorithm. And summary and conclusions are given in Section 5.

Notation: $I$ is the unit matrix. The symbol mean the variables in this paper are estimated parameters of the Kalman filter, and the symbol $*$ indicates the symmetric term of a symmetric matrix.

\section{Description of Aero-Engine Model and Control System}

2.1. Aero-Engine with Performance Degradation. The aeroengine studied in this paper is a high bypass two-spool turbofan engine. The main components of the engine includes a fan, a three-stage low pressure axial compressor (LPC), a nine-stage high-pressure axial compressor (HPC), a singleannular combustion chamber, a one-stage high-pressure turbine (HPT), and a four-stage low-pressure turbine (LPT). The configuration of this aero-engine is shown in Figure 1. A NCL model is described in our previous literatures [38] and implemented by MATLAB/Simulink environment [39], and its structure is also shown in Figure 2 of [38].

It has no doubt that the physical fault like fouling and erosion might change the aerodynamic behavior and flow area of the components. The influences on aero-engine's performance can be described by change of one or two independent parameters of the gas path component. These independent parameters are its efficiency $(\eta)$ and flow capacity $(F)[38,40]$. Such parameters can describe performances of corresponding components, e.g., compressors and turbines. Any deviation of $\eta$ and $F$ from the nominal values is an indication of state of the unhealthy component. Changes in $\eta$ and $F$ of a component lead to the change of other dependent parameters, such as temperature and pressure.

\subsection{Simulation Result of the Component Health Parameter} Degradation. Generally, fouling or erosion occurred in a component can be represented by an appropriate alternation in component $\eta$ and $F$ [41]. The ratio of the change of $F$ to the change of $\eta$ is set referring to open literatures, which is subjective to researchers. In order to verify the established NCL model is capable of estimating the degradation status of the aero-engine, simulations on various health parameters are conducted. Table 1 shows the component degradation with respect to four typical health parameters, including $F$ and $\eta$ changes of the HPC and HPT.

Figure 2 shows the effect of the component degradation on the aero-engine inlet/outlet temperature, pressure, and physical spool speeds. It is observed that all health parameters vary linearly with increasing degree of the degradation.

2.3. Structure of the Engine Control System. An aero-engine control system generally consists of set-point, transient and protection controls. The set-point controller is designed for the steady-state operating condition. However, an aeroengine is considered at the transient state sometimes, when some or all of its performance variables are variable with time. Compared to the steady condition, the transient controller experiences much large and significant performance change in a relatively short time period. To protect engines from undesirable operating conditions such as stalls, surges, exceeding of turbine temperature limit, combustion flameout, and overspeed of shaft rotation, it is necessary to provide the protection control loop. The literatures [38, 40] details the typical aero-engine control system structure. Differing from most researches which focus on aero-engine 


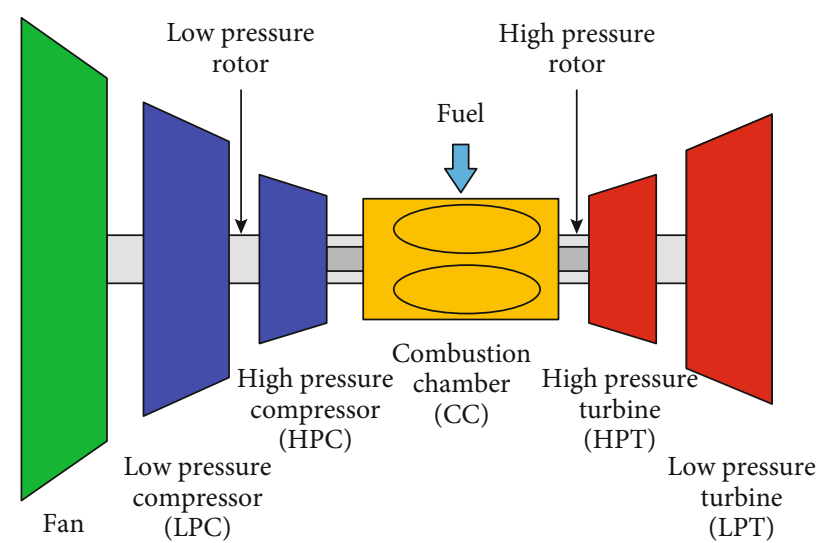

FIgURE 1: The structural diagram of the typical two-spool engine.

component health parameter degradation, this study attempts to introduce the impact of sensor and actuator faults into health parameter degradation to analyze the performance of an aero-engine.

\section{Design of Improved Hybrid FTC}

3.1. Proposed Schematic Fault-Tolerant Control System. Actuators in an engine system transform electric or potential energy into mechanical energy to adjust the positions or valves opening of inlets, nozzles, and vanes. The FTC based on fault estimation is shown in Figure $3[9,38]$. The fault estimation is considered as a comparator between the actual output and the estimated output. When the minimized comparison is to a desired level, the estimation process is finished, together with a credible estimation result. However, there exists the estimation error will occur in the FTC system when the closed-loop system receives the estimation information while the fault estimation is still running.

In this paper, an improved hybrid FTC structure is provided to maintain the performance at a specific level and keep the stability of the closed-loop system when aeroengine components deteriorate associated with simultaneous fault of some sensors and actuators. There are three modules in an improved hybrid FTC structure. The first one is an FDI module consisting of a set of HKFs, which can be used to locate the faulty actuators and sensors. The second module is a fault-tolerant controller, which can handle fault estimation and FTC simultaneously. The last one is a channelswitching module, which is utilized to change the process of an FDI to an FTC. Figure 3 shows the diagram of the improved hybrid FTC structure.

In the actual operation of the aero-engine, the failure of the actuator or sensor and the degradation of the aeroengine typical component health parameters may occur at the same time. If the FDI module is used in this case, the right decision can be made by the improved hybrid FTC structure. Considering the limitation of the number of measured output, the improved hybrid FTC structure is able to receive the information of fault location to ensure that the estimation of the improved hybrid FTC structure is related to the fault result. And before the FTC process starts, the
FDI must provide the corresponding information. If a fault exists, the switching module triggers the estimation process. The improved hybrid FTC algorithm then adjusts its structure based on the information provided by the FDI and completes the FTC process, and the process is shown in Figure 4. For a comprehensive understanding of the improved hybrid FTC system, its structure and algorithm are addressed in following paragraphs.

\subsection{Design of Improved Hybrid FTC}

3.2.1. Improved HFE Structure. It has been found that FDIbased methods are feasible to determine deviation of the aero-engine typical component health parameters. However, these diagnostic methods may encounter some situations when identifying the degradation of the aero-engine typical components and the concurrent faults of actuators and sensors. Previous studies on the FDI system have indicated that its accuracy is acceptable in engine diagnosis, but it is usually associated with complex calculation process and ineffective to identify the fault $[4,9,25,33]$.

An FDI module in improved hybrid FTC structure is provided in [2], in which a hybrid fault estimator (HFE) with functions to adjust the output is employed to perform fault estimation. There are two subparts in the HFE, which are Kalman filter and OBEM, and by using nonlinear OBEM, HFE can improve the estimation accuracy. The structure of a HFE is depicted in Figure 5. The improved HFE in this paper is a nonlinear estimator including HKF and the OBEM, and HKF is used to adjust the output of the OBEM instead of estimate the output of the actual engine. In this structure, the HKF transmits the estimated health information to the OBEM, and the OBEM calculates the measured output for HKF. In the improved HFE, the Kalman filter is like a controller in a conventional closedloop system, controlling the output of OBEM to track the output of the actual aero-engine [36].

The linear model including both of actuator and sensor fault is

$$
\left\{\begin{array}{l}
\Delta \dot{x}(t)=A \Delta x(t)+B\left(\Delta u(t)+f_{a}(t)\right)+L \Delta h(t), \\
\Delta y(t)=C \Delta x(t)+D\left(\Delta u(t)+f_{a}(t)\right)+M \Delta h(t)+V f_{s}(t),
\end{array}\right.
$$

where $f_{a}(t)=\left[f_{m f} f_{V B V}\right]^{T}$ denotes to the actuators bias, and $f_{s}(t)=\left[f_{N_{H}} f_{N_{L}} f_{T_{F A N}} f_{P_{F A N}}\right]^{T}$ is the measured output error caused by the sensor fault. To be easily understood, the input of the established aero-engine model is simplified by two variables. It should be noted that it does not affect the effectiveness of the proposed method because the proposed model does not rely on the number of variables.

Assuming that the number of state variables of the Kalman filter is at least equal to the number of sensors, the hybrid Kalman filter is

$$
\left\{\begin{array}{l}
\Delta \dot{\hat{x}}(t)=A_{\text {Kal }} \Delta \widehat{x}(t)+K_{\text {Kal }}(y(t)-\widehat{y}(t)), \\
\hat{y}(t)=C_{\text {Kal }} \Delta \widehat{x}(t)+y_{\text {OBEM }}(t)
\end{array}\right.
$$




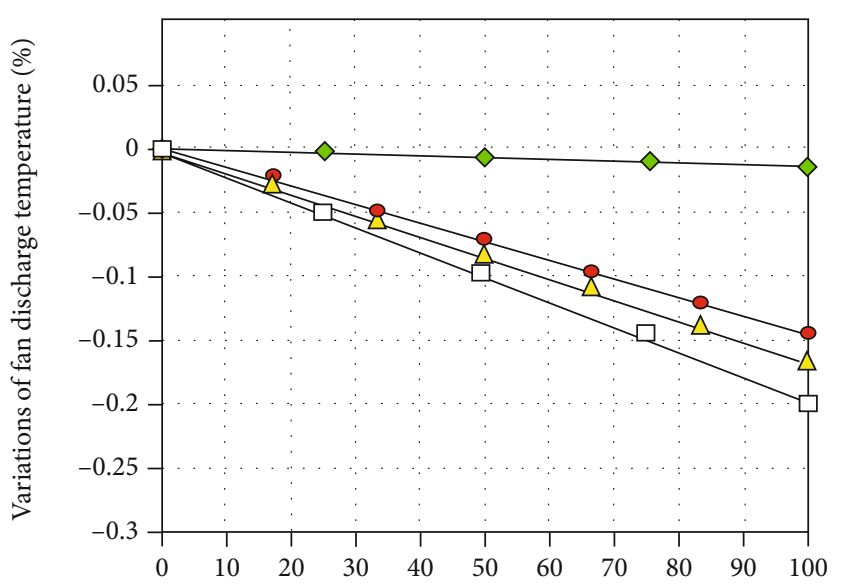

Fault severity (\%)

(a) Variations of fan discharge temperature at design point

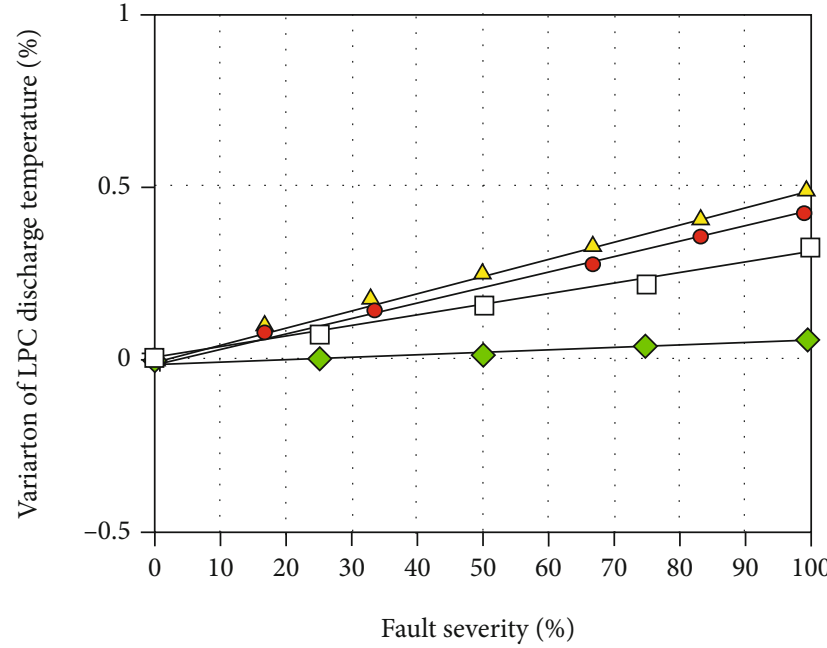

(c) Variations of LPC discharge temperature at design point

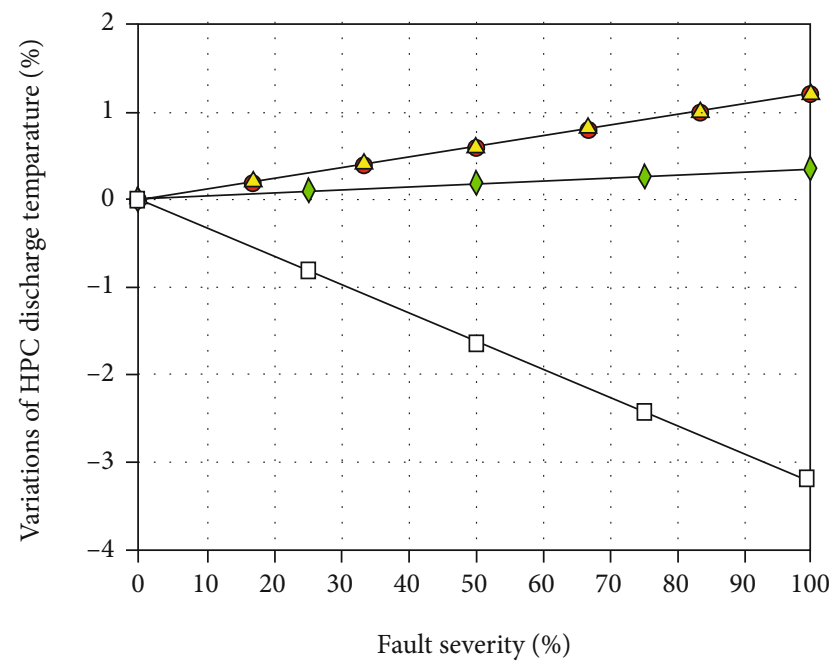

(e) Variations of HPC discharge temperature at design point

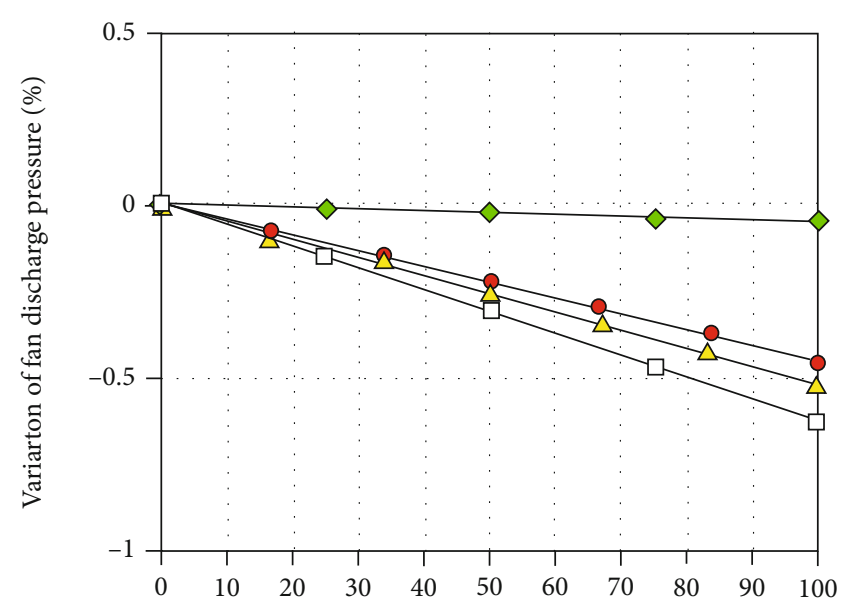

Fault severity (\%)

(b) Variations of fan discharge pressure at design point

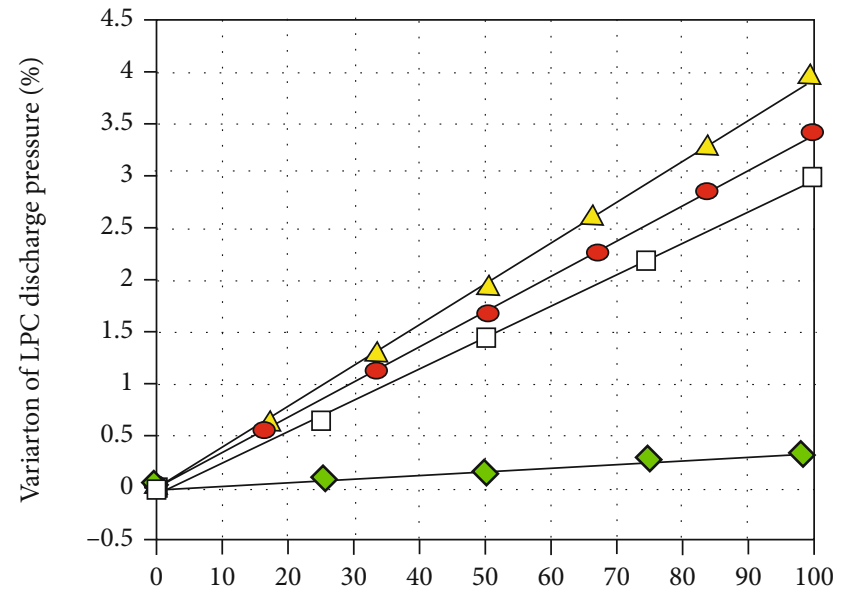

Fault severity (\%)

(d) Variations of LPC discharge pressure at design point

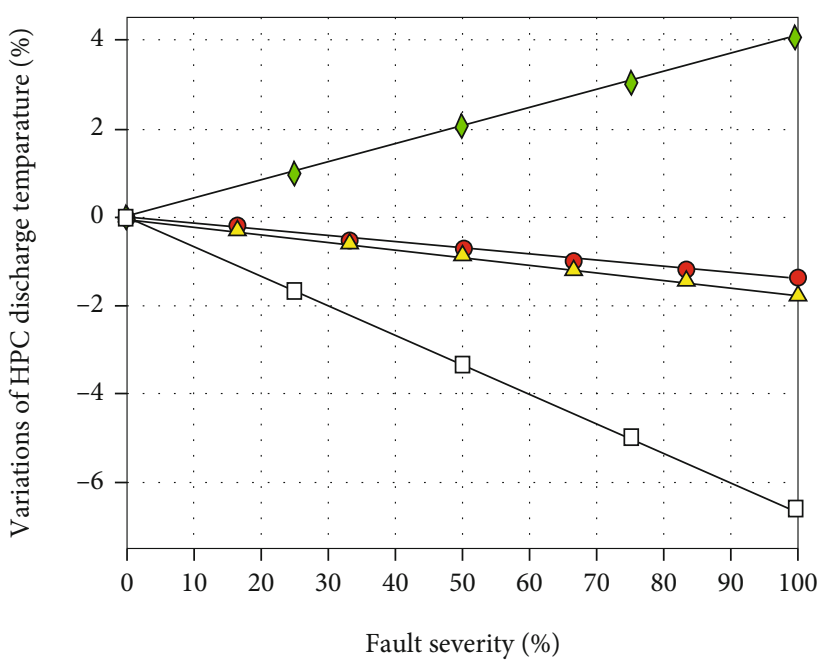

(f) Variations of HPC discharge pressure at design point

FIgURe 2: Continued. 


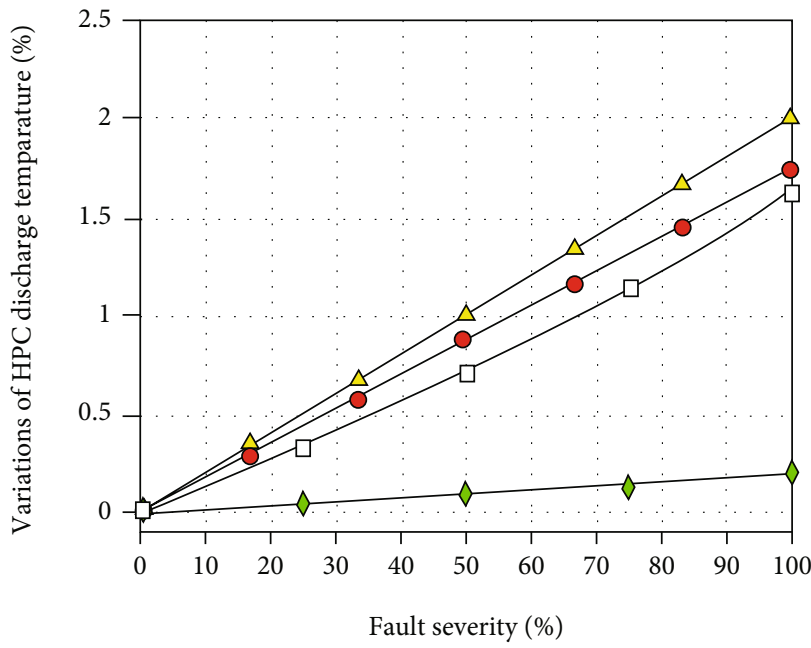

(g) Variations of HPT discharge temperature at design point

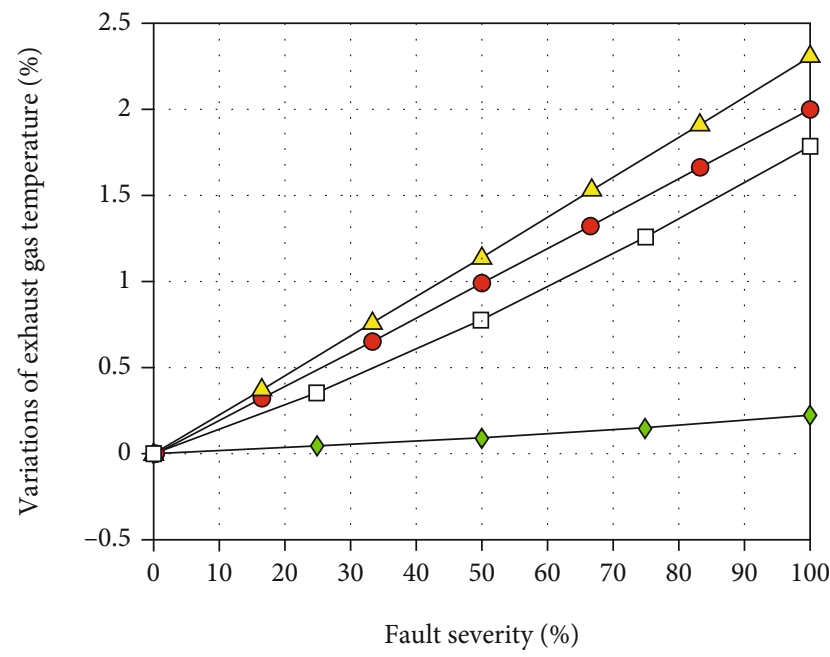

(i) Variations of exhaust gas temperature at design point

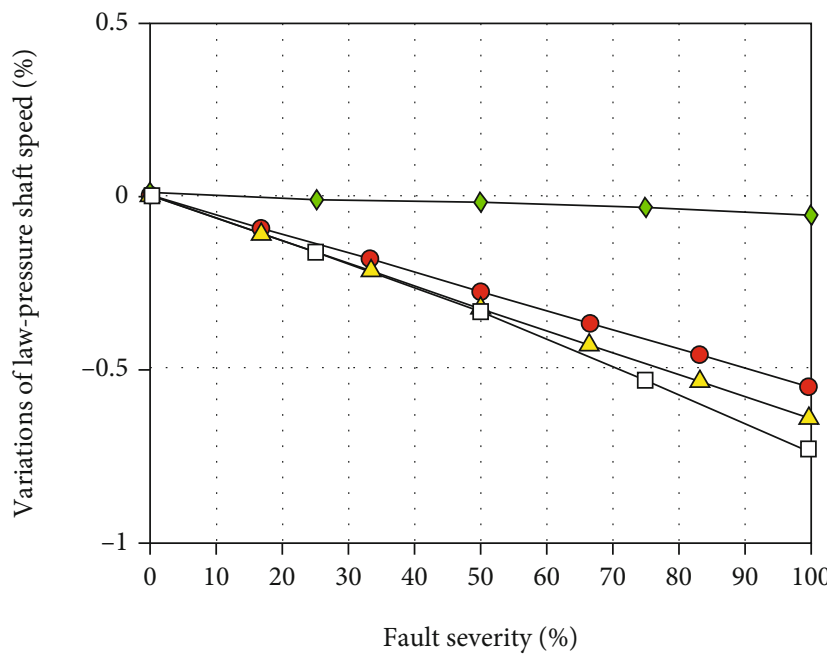

(k) Variations of low-pressure spool speed at design point

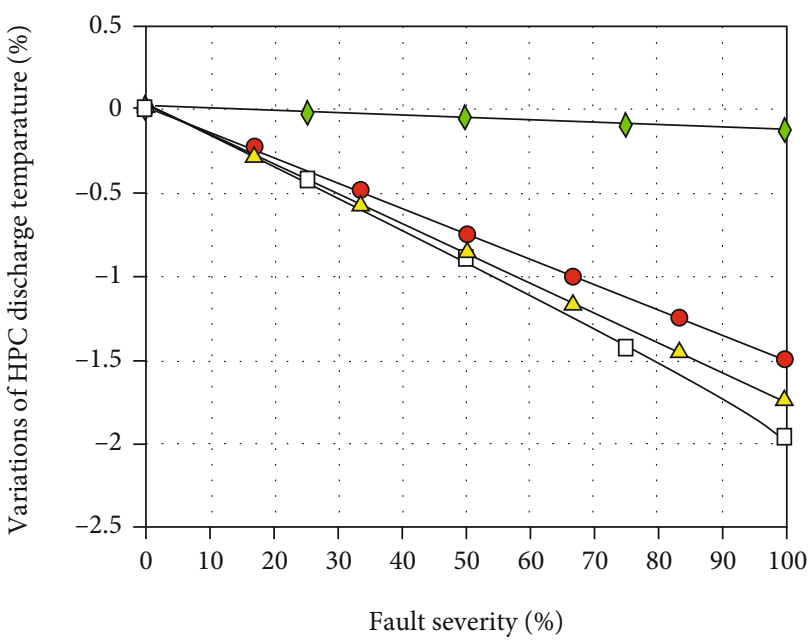

(h) Variations of HPT discharge pressure at design point

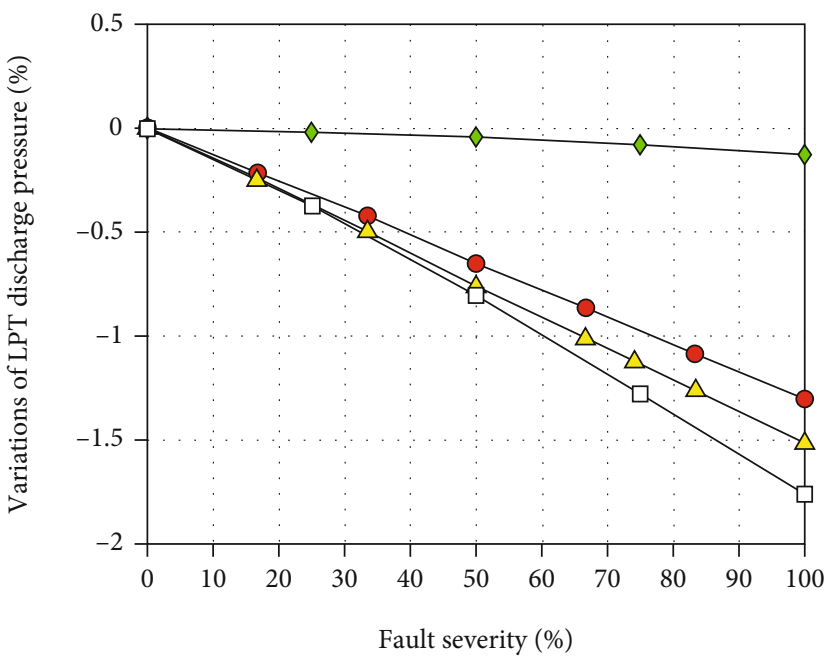

(j) Variations of LPT discharge pressure at design point

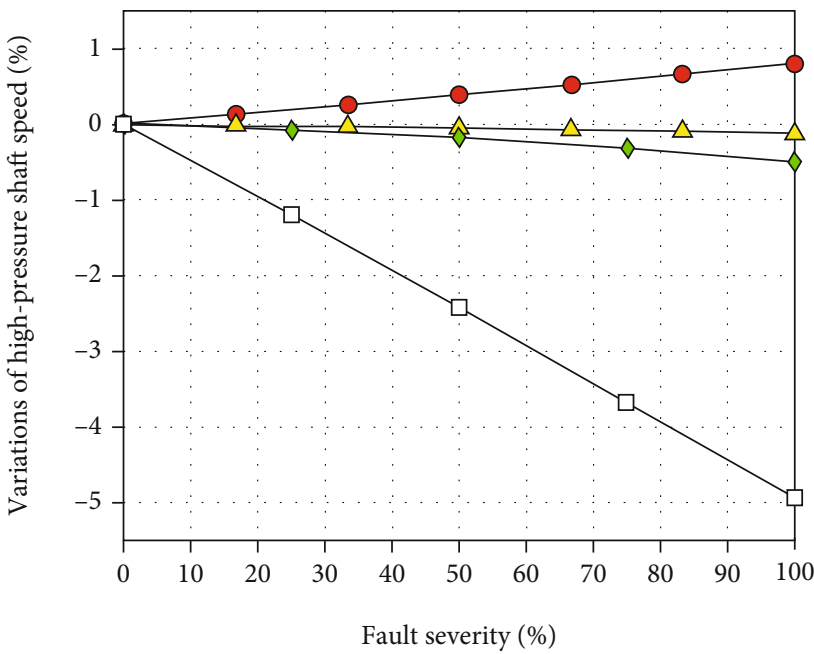

$$
\begin{array}{ll}
\multimap \text { HPC fouling } & \checkmark \text { HPC fouling } \\
\neg \text { HPC erosion } & -\square \text { HPT erosion }
\end{array}
$$

(l) Variations of high-pressure spool speed at design point

Figure 2: Simulation results of component's degradation. 
TABLE 1: Components health parameter degradation.

\begin{tabular}{|c|c|c|c|c|}
\hline Component & $\begin{array}{l}\text { Flow capacity } \\
\qquad(F)\end{array}$ & $\begin{array}{l}\text { Efficiency } \\
(\eta)\end{array}$ & $\begin{array}{c}\text { Ratio } \\
(\Delta F: \Delta \eta)\end{array}$ & Range \\
\hline \multirow{2}{*}{$\begin{array}{l}\text { HPC } \\
\text { fouling }\end{array}$} & $F_{\text {HPC }} \downarrow$ & $\eta_{\text {HPC }} \downarrow$ & $3: 1$ & $\begin{array}{l}(0- \\
6 \%)\end{array}$ \\
\hline & & & & $\begin{array}{l}(0- \\
2 \%)\end{array}$ \\
\hline \multirow{2}{*}{$\begin{array}{l}\text { HPC } \\
\text { erosion }\end{array}$} & $F_{\text {HPC }} \downarrow$ & $\eta_{\text {HPC }} \downarrow$ & $2: 1$ & $\begin{array}{l}(0- \\
6 \%)\end{array}$ \\
\hline & & & & $\begin{array}{l}(0- \\
3 \%)\end{array}$ \\
\hline \multirow{2}{*}{$\begin{array}{l}\text { HPT } \\
\text { fouling }\end{array}$} & $F_{\mathrm{HPT}} \downarrow$ & $\eta_{\text {HPT }} \downarrow$ & $2: 1$ & $\begin{array}{l}(0- \\
4 \%)\end{array}$ \\
\hline & & & & $\begin{array}{l}(0- \\
2 \%)\end{array}$ \\
\hline \multirow{2}{*}{$\begin{array}{l}\text { HPT } \\
\text { erosion }\end{array}$} & $F_{\mathrm{HPT}} \uparrow$ & $\eta_{\text {HPT }} \downarrow$ & $2: 1$ & $\begin{array}{l}(0- \\
4 \%)\end{array}$ \\
\hline & & & & $\begin{array}{l}(0- \\
2 \%)\end{array}$ \\
\hline
\end{tabular}

$$
\text { where } \widehat{x}=\left[\begin{array}{c}
x \\
h \\
f_{a}(i) \\
f_{s}(j)
\end{array}\right], \quad A_{K a l}=\left[\begin{array}{ccccc}
A & L & B 0 & \\
0 & 0 & 0 & 0 \\
0 & 0 & 0 & 0 & \\
0 & 0 & 0 & 0 &
\end{array}\right] \text {, }
$$

and $C_{K a l}=C \quad M \quad D \quad V \cdot K_{K a l}=\left[\begin{array}{l}K_{1} \\ K_{2}\end{array}\right]$ is a gain matrix

of the Kalman filter, gotten based on [6]. The element $k_{1}$ in $K_{K a l}$ is the coefficient of spool speed, and $k_{2}$ denotes the coefficient of health parameter or fault. $y(t)$ is the measured aero-engine output. $y_{\mathrm{OBEM}}(t)$ is the output of the OBEM, and the OBEM is

$$
\left\{\begin{array}{l}
\dot{x}_{\mathrm{OBEM}}(t)=f\left(x_{\mathrm{OBEM}}(t), u_{\mathrm{mod}}(t), h_{\mathrm{ref}}(t)\right), \\
y_{\mathrm{OBEM}}(t)=g\left(x_{\mathrm{OBEM}}(t), u_{\mathrm{mod}}(t), h_{\mathrm{ref}}(t)\right),
\end{array}\right.
$$

where $x_{\mathrm{OBEM}}(t)$ and $y_{\mathrm{OBEM}}(t)$ are state variable and output of the OBEM, respectively. Assuming that the aeroengine and the OBEM run in parallel, the variable $h_{\text {ref }}(t)$ represents the health condition derived by the offline tuning for the OBEM, and the control output $u_{\bmod }(t)$ shown in Figure 6 is obtained from its corresponding actuator model. It is shown that the structure is simplified because the output variation caused by nominal control, environmental input, and component parameters are calculated from the OBEM $[2,36,37]$. In addition, the output of the OBEM is not influenced by any faulty actuator.

A linear parameter-varying (LPV) model formulated based on multiple linear models at various operating points of the aero-engine is introduced into the HKF to adapt to different working conditions of the aero-engine [42, 43]. By using the LPV form, the model of an HKF can be described by

$$
\left\{\begin{array}{l}
\Delta \dot{\vec{x}}(t)=A_{\text {Kal }}(\delta) \Delta \widehat{x}(t)+K_{\text {Kal }}(\delta)(y(t)-\widehat{y}(t)), \\
\hat{y}(t)=C_{\text {Kal }}(\delta) \Delta \widehat{x}(t)+y_{\mathrm{OBEM}}(t),
\end{array}\right.
$$

and its logic is shown in Figure 6.

An HFE is developed to perform fault estimation based on an HKF in the improved hybrid FTC structure, and it is similar to the HKF; the OBEM in the HFE can be represented by

$$
\left\{\begin{array}{l}
\dot{x}_{\mathrm{OBEM}}(t)=f\left(x_{\mathrm{OBEM}}(t), \widehat{u}(t), \widehat{h}(t)\right), \\
y_{\mathrm{OBEM}}(t)=g\left(x_{\mathrm{OBEM}}(t), \widehat{u}(t), \widehat{h}(t), \widehat{f}_{s}(t)\right),
\end{array}\right.
$$

where $\widehat{u}(t)=u_{\text {mod }}(t)+\widehat{f}_{a}(t), \widehat{h}(t)$, and $\widehat{f}_{s}(t)$ are the actuator model output, the component health parameter deviation, and sensor fault obtained from the HKF based on the OBEM, respectively. Because the output deriving from OBEM does not affect the variables $\widehat{h}(t), \widehat{f}_{a}(t)$, and $\widehat{f}_{s}(t)$, it is not necessary to estimate the measurable output of an engine by HKF. As a result, the structure of HKF in the nonlinear estimated system can be simplified by

$$
\Delta \dot{\wedge} \wedge^{\prime}(t)=A_{\text {Kal }}^{\prime} \Delta x \wedge^{\prime}(t)+K_{\text {Kal }}^{\prime}\left(y(t)-y_{\mathrm{OBEM}}(t)\right),
$$

where $x \wedge^{\prime}(t)=\left[\begin{array}{lll}f_{s}(t) & f_{a}(t) & h(t)\end{array}\right]^{T}$ and $K_{K a l}^{\prime}=k_{2}$. Since $A_{K a l}^{\prime}$ and $K_{K a l}^{\prime}$ are parts of $A_{K a l}$ and $K_{K a l}$, respectively, $A_{K a l}^{\prime}$ becomes a zero matrix, and $C_{K a l}^{\prime}$ is changed to the identity matrix $[2,37]$. Hence, the Kalman filter becomes

$$
\Delta \dot{x} \wedge^{\prime}(t)=K_{K a l}^{\prime}\left(y(t)-y_{\text {OBEM }}(t)\right),
$$

and the HFE can be rewritten as

$$
\left\{\begin{array}{l}
\Delta \dot{x \wedge^{\prime}}(t)=K_{\mathrm{Kal}}^{\prime}\left(y(t)-y_{\mathrm{OBEM}}(t)\right), \\
\hat{y}(t)=y_{\mathrm{OBEM}}(t) .
\end{array}\right.
$$

It is found in the equations above that the form is very similar to a traditional closed loop system.

3.2.2. Convergence Proof of Improved HFE. The HKF used in this paper performs a first-order approximation to the last estimate of the nonlinear model. However, few articles have discussed the convergence of this method. The main difficulty is that the HKF equation is only an approximate equation. Therefore, the corresponding propagation equation is available only when the estimated value belongs to the neighborhood of the actual state.

According to the principle of the HKF, the Kalman filter for state and output estimations of the system can be described as follows:

(1) Prior estimation error 


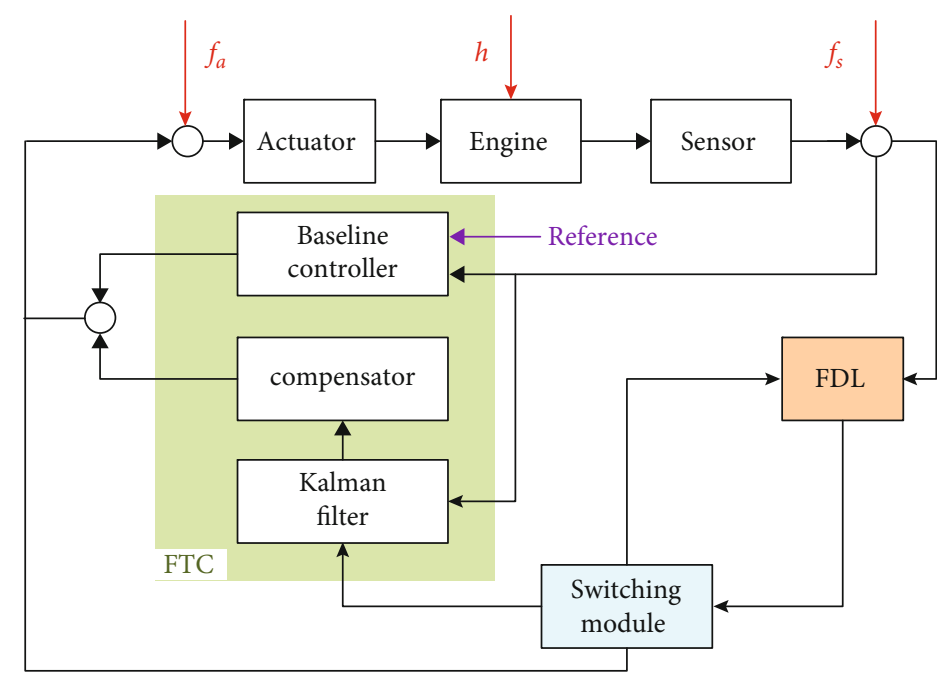

FIgURE 3: The proposed schematic of the improved hybrid FTC structure.

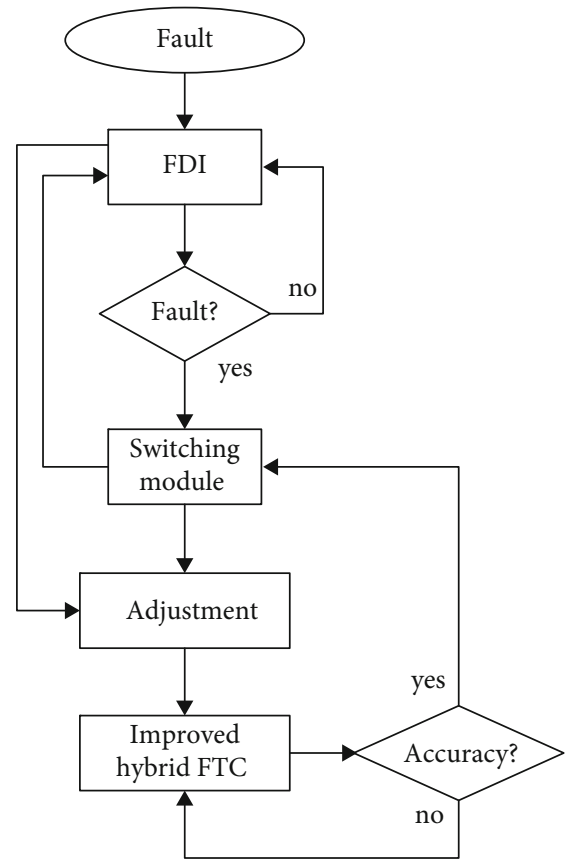

FIGURE 4: Working process in the improved hybrid FTC structure.

$$
e^{-}(t)=\Delta x(t)-\Delta x^{-}(t)
$$

(2) Posterior estimation error

$$
e(t)=\Delta x(t)-\Delta \widehat{x}(t)
$$

$$
\tilde{e}(t)=\Delta y(t)-\Delta \widehat{y}(t)
$$

And the candidate Lyapunov function can be selected by

$$
\begin{gathered}
V(t)=e(t)^{T} P e(t), \\
V(t+k)=e^{T}(t+k) P e(t+k) .
\end{gathered}
$$

The purpose of the analysis is to determine the constraint of $\{V(t+k)\}_{k=1, \cdots}$ to deduce that it is in decreasing sequence. Usually, the analysis of KF uses first-order expansion to be approximately equal to

$$
\begin{gathered}
\tilde{e}(t+k) \approx H e^{-}(t+k), \\
e^{-}(t+k) \approx A e(t) .
\end{gathered}
$$

Due to the first-order linearization, there exist state and output estimation errors in KF. In order to have a rigorous convergence analysis, these neglected errors should be considered to obtain accurate equations. Hence, the unknown diagonal matrices $\alpha_{i}=\operatorname{diag}\left\{\alpha_{i}, \cdots, \alpha_{i+1}\right\}$ and $\beta_{j}=\operatorname{diag}\left\{\beta_{1}\right.$, $\left.\cdots, \beta_{j}\right\}$ are introduced to prove that Lyapunov function is in a decreasing sequence. It can be obtained by

$$
\begin{aligned}
& H e^{-}(t+k)=\alpha_{i} \tilde{e}(t+k), \\
& e^{-}(t+k)=\beta_{j} A e(t) .
\end{aligned}
$$

Actually, a strictly decreasing Lyapunov function depends closely on the choosing of $R$ and $Q$. So

$$
\begin{gathered}
e(t+k)=e^{-}(t+k)-P^{-} H^{T}\left(H P^{-} H^{T}+R\right)^{-1} \tilde{e}(t+k), \\
P H^{T} R^{-1}=P^{-}\left(H P^{-} H^{T}+R\right)^{-1}, \\
P^{-1}=\left(P^{-}\right)^{-1}+H^{T} R^{-1} H .
\end{gathered}
$$

(3) Output estimation error 


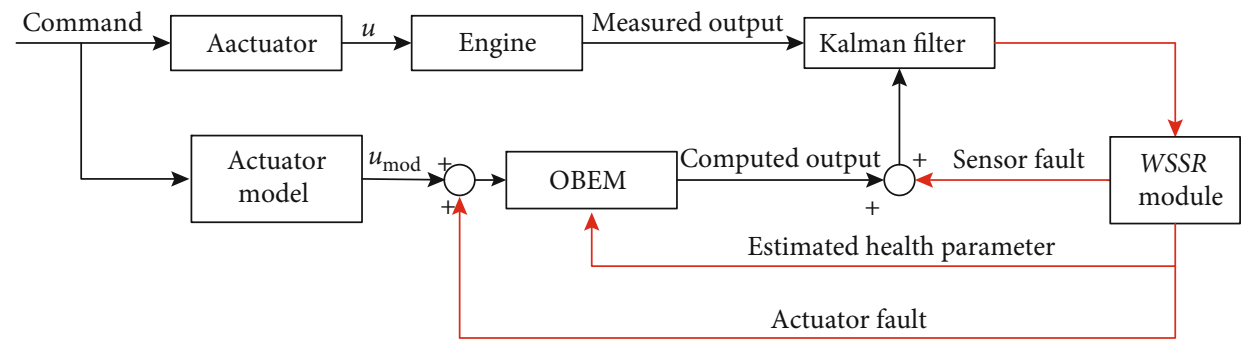

Figure 5: General structure of an improved HFE.

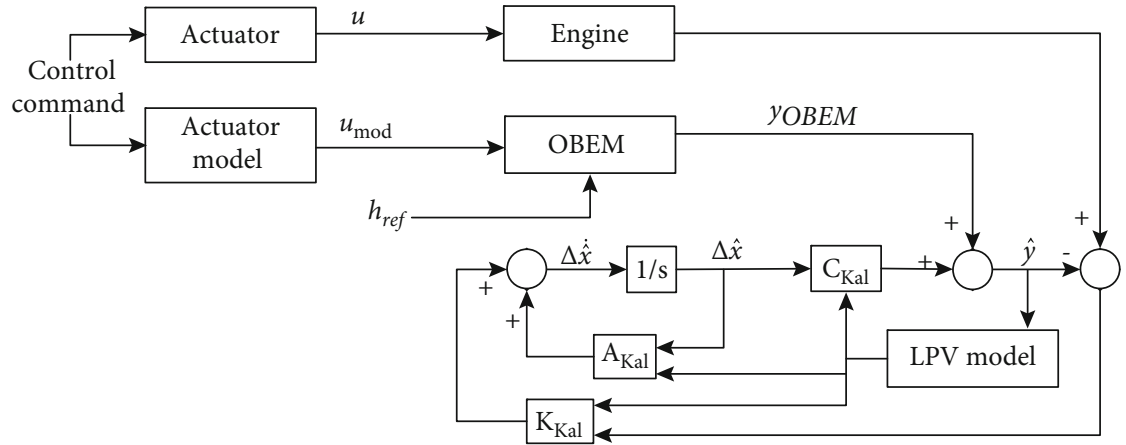

FIgURE 6: Structure of the HKF.

Combined with above two equations, the Lyapunov candidate function can be obtained by

$$
\begin{aligned}
V(t+k)= & \left(e^{-}(t+k)-P H^{T} R^{-1} \tilde{e}(t+k)\right)^{T} P\left(e^{-}(t+k)\right. \\
& \left.-P H^{T} R^{-1} \tilde{e}(t+k)\right),
\end{aligned}
$$

or equivalent to

$$
\begin{aligned}
& V(t+k)=\left(e^{-}(t+k)\right)^{T} P^{-} e^{-}(t+k) \\
&-\left(e^{-}(t+k)\right)^{T} H^{T} R^{-1} \tilde{e}(t+k) \\
&-\tilde{e}^{T}(t+k) R^{-1} H e^{-}(t+k) \\
&+\tilde{e}^{T}(t+k) R^{-1} H P H^{T} R^{-1} \tilde{e}(t+k), \\
& V^{-}(t+k)=\left(e^{-}(t+k)\right)^{T} P^{-} e^{-}(t+k) .
\end{aligned}
$$

Combining (14), (15), (18), and (19), we have

$$
\begin{gathered}
V(t+k)=V^{-}(t+k)+\tilde{e}^{T}(t+k) \\
\cdot\left(\alpha_{i} R^{-1} \alpha_{i}-\alpha_{i} R^{-1}-R^{-1} \alpha_{i}+R^{-1} H P H^{T} R^{-1}\right) \tilde{e}(t+k), \\
V^{-}(t+k)=e^{T}(t) A^{T} \beta_{j}\left(A P A^{T}+Q\right)^{-1} \beta_{j} A e(t) .
\end{gathered}
$$
that

$\{V(t+k)\}_{k=1, \cdots}$ is in the decreasing sequence. It means $V(t+k)-V(t)=V(t+k)-V^{-}(t+k)+V^{-}(t+k)-V(t) \leq 0$,

$$
\begin{aligned}
& \text { i.e., } \\
& \begin{aligned}
V(t+k) & -V(t)=\tilde{e}^{T}(t+k)\left(\alpha_{i} R^{-1} \alpha_{i}-\alpha_{i} R^{-1} R^{-1} \alpha_{i}\right. \\
& \left.+R^{-1} H P H^{T} R^{-1}\right) \tilde{e}(t+k) .
\end{aligned}
\end{aligned}
$$

In order to derive $V(t+k)-V(t) \leq 0$, it should exist

$$
\begin{gathered}
\alpha_{i} R^{-1} \alpha_{i}-\alpha_{i} R^{-1}-R^{-1} \alpha_{i}+R^{-1} H P H^{T} R^{-1} \leq 0, \\
A^{T} \beta_{j}\left(A P A^{T}+Q\right)^{-1} \beta_{j} A-P^{-1} \leq 0 .
\end{gathered}
$$

Before deriving the conclusion of this paper, two useful lemmas are established in advance.

Lemma 1. Assuming that each element in $\alpha_{i}$ is bounded in

$$
1-\sqrt{1-\Delta_{t+k}} \leq \alpha_{i} \leq 1+\sqrt{1-\Delta_{t+k}},(i=1, \cdots, p),
$$

with

$$
\Delta_{t+k}=\lambda_{\max }(R) \lambda_{\max }\left(R^{-1} H P H^{T} R^{-1}\right) .
$$

$R$ is selected to satisfy $\Delta_{t+k} \leq 1$, and $\lambda_{\max }(\cdot)$ is the symbol of maximum eigenvalue. Then, (23) is verified.

Proof. As the eigenvalues $s_{r}$ corresponded to $\alpha_{r i}$ of $\alpha_{i}$ are of following properties

$$
\alpha_{i} s_{r}=\alpha_{r i} s_{r}
$$




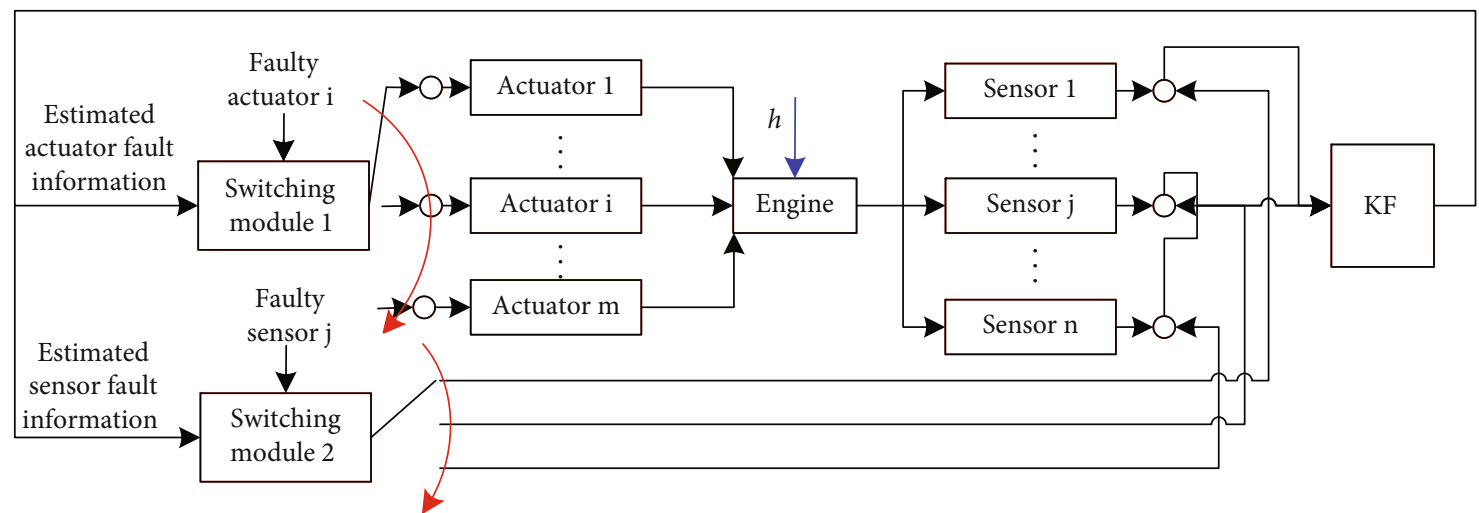

FIgURE 7: Output switching logic of the Kalman filter in the improved hybrid FTC structure.

$$
s_{r}^{T} \alpha_{i}=s_{r}^{T} \alpha_{r i}
$$

From (23),

$s_{r}^{T}\left(\alpha_{i} R^{-1} \alpha_{i}-\alpha_{i} R^{-1}-R^{-1} \alpha_{i}+R^{-1} H P H^{T} R^{-1}\right) s_{r} \leq 0$.

Combining (27), (28) with (29) deduces

$$
\alpha_{r i}^{2} R^{-1}-2 \alpha_{r i} R^{-1}+R^{-1} H P H^{T} R^{-1} \leq 0 .
$$

According to the measure of matrix properties [44], the left side of (30) can be transformed into

$$
\begin{aligned}
& \mu\left(\alpha_{r i}^{2} R^{-1}-2 \alpha_{r i} R^{-1}+R^{-1} H P H^{T} R^{-1}\right) \leq \mu\left(\alpha_{r i}^{2} R^{-1}-2 \alpha_{r i} R^{-1}\right) \\
& \quad+\mu\left(R^{-1} H P H^{T} R^{-1}\right) .
\end{aligned}
$$

The symbol $\mu(\cdot)$ is defined as $\mu(A)=\lambda_{\max }\left(A^{T}+A / 2\right)$. (31) can be transferred into

$$
\begin{aligned}
& \lambda_{\max }\left(\alpha_{r i}^{2} R^{-1}-2 \alpha_{r i} R^{-1}+R^{-1} H P H^{T} R^{-1}\right) \\
& \quad \leq \lambda_{\max }\left(\alpha_{r i}^{2} R^{-1}-2 \alpha_{r i} R^{-1}\right)+\lambda_{\max }\left(R^{-1} H P H^{T} R^{-1}\right)
\end{aligned}
$$

Therefore, under the constraint of (25), (26) and combined with (32), (23) is satisfied. This completes the proof. $\square$

Lemma 2. Assuming that each element in $\beta_{m j}$ of $\beta_{j}$ is bounded in

$$
-\sqrt{\eta_{k}} \leq \beta_{m j} \leq \sqrt{\eta_{k}},(j=1, \cdots, n)
$$

with

$$
\eta_{k}=\frac{\lambda_{\min }\left(A P A^{T}+Q\right)}{\lambda_{\min }\left(A P A^{T}\right)} .
$$

Then, (24) is verified.
Proof. As the eigenvalues $u_{m}$ corresponded to $\beta_{m j}$ of $\beta_{j}$ are of following properties:

$$
\begin{gathered}
\beta_{j} u_{m}=\beta_{m j} u_{m}, \\
u_{m}^{T} \beta_{j}=u_{m}^{T} \beta_{m j} .
\end{gathered}
$$

Knowing that $A$ is reversible, (24) is equivalent to

$$
\beta_{j}\left(A P A^{T}+Q\right)^{-1} \beta_{j}-A^{-T} P^{-1} A^{-1} \leq 0 .
$$

Combining (35) and (36) with (38), it can be gotten

$$
\beta_{m j}^{2}\left(A P A^{T}+Q\right)^{-1}-A^{-T} P^{-1} A^{-1} \leq 0 .
$$

As mentioned in Lemma 1,

$$
\beta_{m j}^{2} \lambda_{\max }\left(A P A^{T}+Q\right)^{-1}-\lambda_{\max }\left(A^{-T} P^{-1} A^{-1}\right) \leq 0 .
$$

Hence, the convergence of improving HFE is proved. $\square$

3.2.3. Design of FTC. In a fault estimation-based FTC system, the controller can correct the control signal according to the fault information provided by the improved HFE system, and it can reduce the effect by the degradation or fault and maintain the aero-engine performance.

According to Figure 3, there are two parts in the FTC module, one is the baseline controller which is realized through static state feedback method. The baseline controller is

$$
\Delta u_{b}(t)=K_{b} \Delta x(t)
$$

where $u_{b}(t)$ denotes the baseline controller, and the closed loop system can be written by

$$
\left\{\begin{array}{l}
\Delta \dot{x}(t)=\left(A+B K_{b}\right) \Delta x(t)+L \Delta h(t), \\
\Delta y(t)=\left(C+D K_{b}\right) \Delta x(t)+M \Delta h(t) .
\end{array}\right.
$$

Taking actuator fault into the above closed loop system 


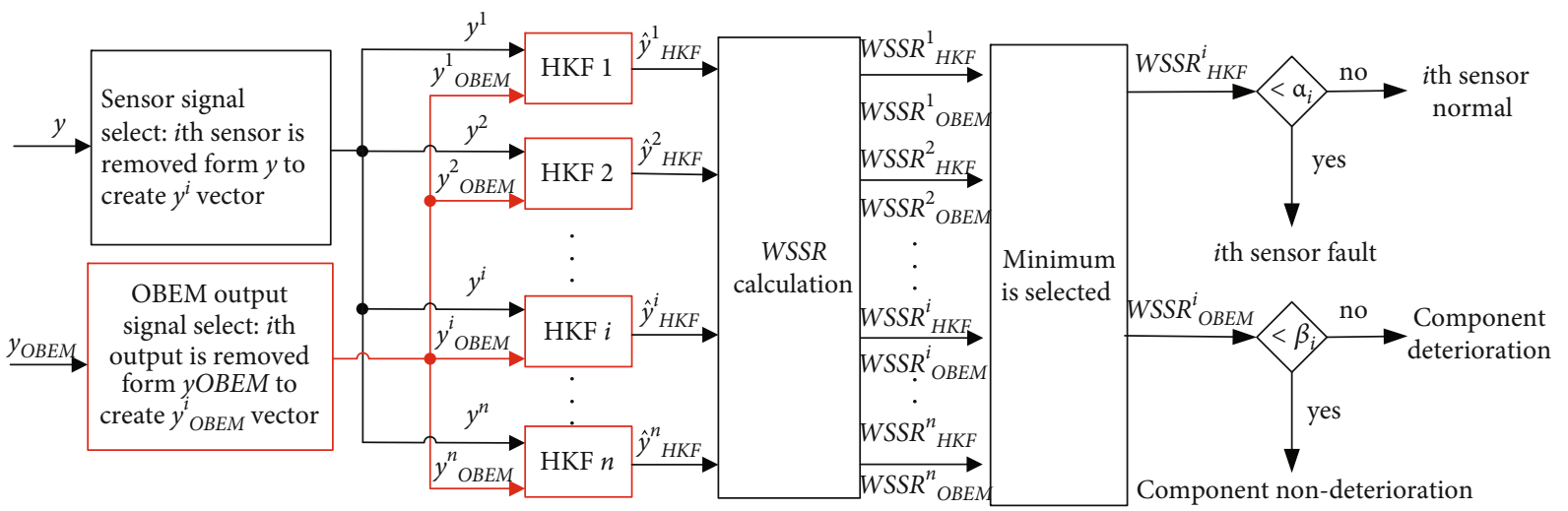

FIgURE 8: The calculation structure of the sensor WSSR.

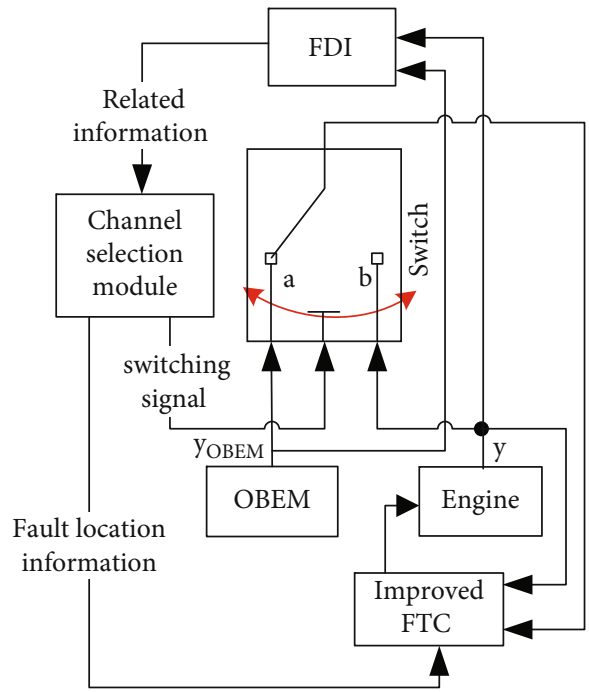

FIGURE 9: Switching channel between FDI and the improved hybrid FTC structure.

(41), the closed loop system can be rewritten as

$$
\left\{\begin{array}{l}
\Delta \dot{x}(t)=\left(A+B K_{b}\right) \Delta x(t)+L \Delta h(t)+B f_{a}(t), \\
\Delta y(t)=\left(C+D K_{b}\right) \Delta x(t)+M \Delta h(t)+D f_{a}(t) .
\end{array}\right.
$$

Another part in the FTC module is the compensator. In order to eliminate the effect of the actuator fault, the fault compensation signal should be added into the control signal, and the control signal can be

$$
\Delta u(t)=\Delta u_{b}(t)-K_{a} \widehat{f}_{a}(t)
$$

and the closed loop with sensor fault can be represented by

$$
\left\{\begin{array}{l}
\Delta \dot{x}(t)=\left(A+B K_{b}\right) \Delta x(t)+L \Delta h(t)+B\left(f_{a}(t)-K_{a} \widehat{f}_{a}(t)\right) \\
\Delta y(t)=\left(C+D K_{b}\right) \Delta x(t)+M \Delta h(t)+D\left(f_{a}(t)-K_{a} \widehat{f}_{a}(t)\right)+V f_{s}(t) .
\end{array}\right.
$$

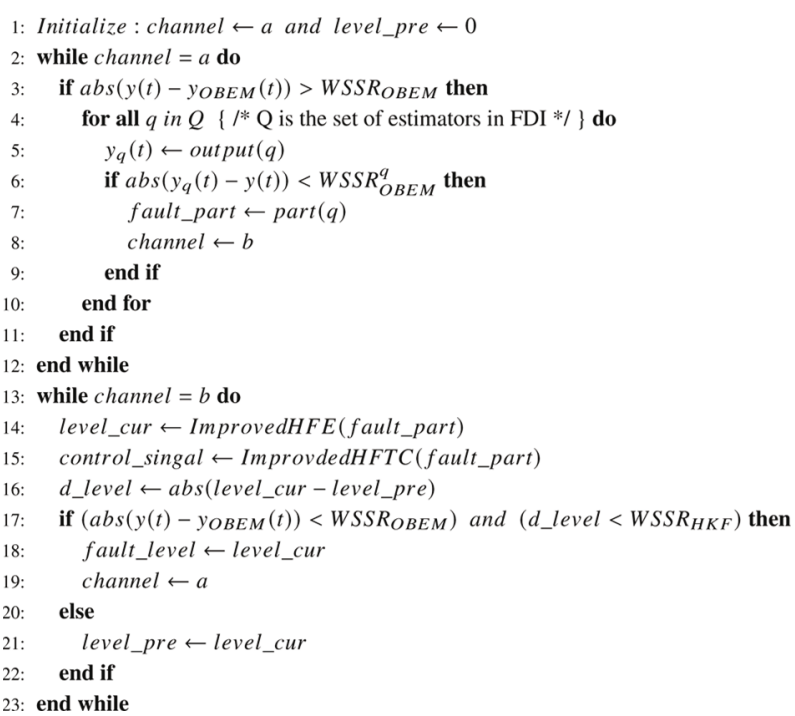

Figure 10: Channel switching algorithm.

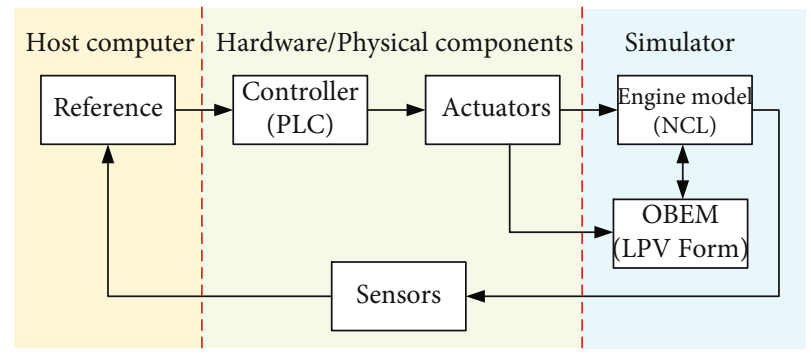

FIGURE 11: Structure of the semiphysical experimental platform (it is reproduced from [32]).

If the sensor fault signal happens to be the corresponding control input signal, in order to eliminate the effect of the sensor fault, the fault-tolerant compensation signal needs to be introduced into the input signal of the controller as

$$
\Delta u(t)=K_{b}\left(\left(\Delta x(t)-K_{s} \widehat{f}_{s}(t)\right)-K_{a} \widehat{f}_{a}(t)\right)
$$




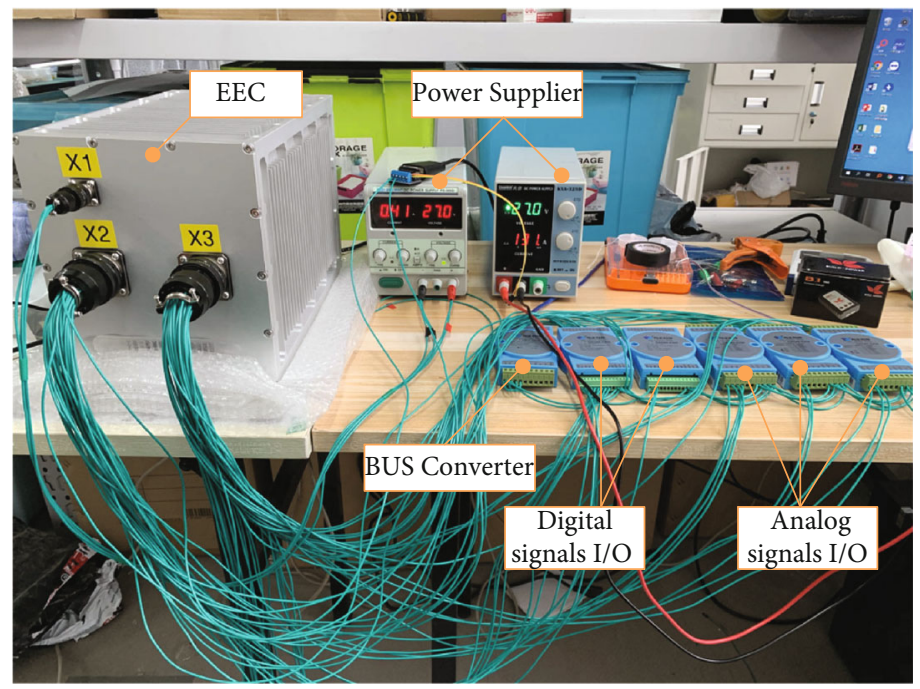

Figure 12: The electronic engine controller in the semiphysical platform (it is reproduced from [32]).

and the compensator is

$$
\Delta u_{\text {com }}(t)=-K_{b}\left(K_{s} \widehat{f}_{s}(t)+K_{a} \widehat{f}_{a}(t)\right)
$$

The closed loop system is

$$
\left\{\begin{array}{l}
\dot{x}_{c l}(t)=A_{c l} x_{c l}(t)+B_{c l} w(t), \\
y(t)=C_{c l} x_{c l}(t)+D_{c l} w(t),
\end{array}\right.
$$

where

$$
\begin{aligned}
x_{c l} & =\left[\begin{array}{c}
\Delta x(t) \\
h(t) \\
f_{a}(t) \\
f_{s}(t)
\end{array}\right], w(t)=\left[\begin{array}{c}
\hat{f}_{a}(t) \\
\hat{f}_{s}(t)
\end{array}\right], A_{c l}=\left[\begin{array}{cccc}
A+B K_{b} & L & B & 0 \\
0 & 0 & 0 & 0 \\
0 & 0 & 0 & 0 \\
0 & 0 & 0 & 0
\end{array}\right], B_{c l} \\
& =\left[\begin{array}{cc}
-B K_{b} K_{a} & -B K_{b} K_{s} \\
0 & 0 \\
0 & 0 \\
0 & 0
\end{array}\right], \\
& C_{c l}=\left[\begin{array}{lll}
C+D K_{b} & M & D
\end{array}\right], D_{c l}=\left[\begin{array}{ll}
-D K_{b} K_{a} & -D K_{b} K_{s}
\end{array}\right] .
\end{aligned}
$$

In this paper, the estimated faults of actuator or sensor $\widehat{f}_{a}(t)$ and $\widehat{f}_{s}(t)$ are regarded as disturbance variables, and the closed system performance requirement is to design the controller (45) for the simultaneous faults of sensor and actuator when the aero-engine component health parameter degradation is stable and an $H_{\infty}$ performance constraint is satisfied

$$
\left\|C_{c l}\left(s I-A_{c l}\right)^{-1} B_{c l}+D_{c l}\right\|_{\infty}<\gamma
$$

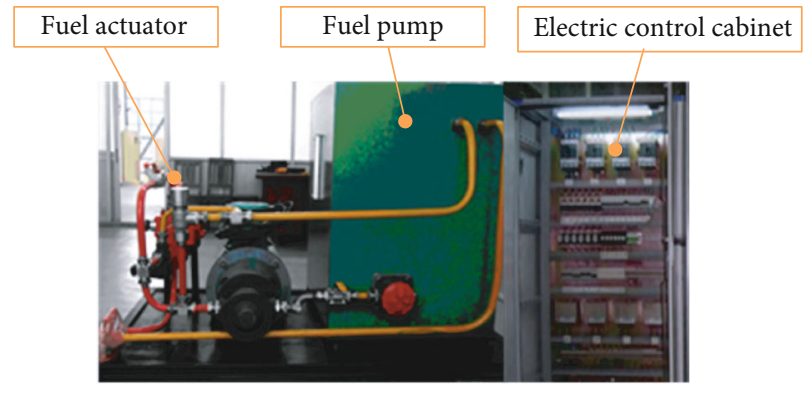

FIGURE 13: The fuel supply system and electric control cabinet in the platform (it is reproduced from [32]).

Theorem 3. The closed loop system (47) is stable with an $H_{\infty}$ performance index $\gamma$, if there exist symmetric positive definite matrix $X$, and matrices $W_{1}, W_{2}$, and $W_{3}$ such that the following LMI (50) holds, and the state feedback controller (45) gain matrices can be obtained by

$$
\left[\begin{array}{ccccccc}
\left(A X+B W_{1}\right)+\left(A+B W_{1}\right)^{T} & L & B & 0 & -B W_{2} & -B W_{3} & \left(C X+D W_{1}\right)^{T} \\
* & 0 & 0 & 0 & 0 & 0 & M^{T} \\
* & * & 0 & 0 & 0 & 0 & D^{T} \\
* & * & * & 0 & 0 & 0 & V^{T} \\
* & * & * & * & -\gamma & 0 & -\left(D W_{2}\right)^{T} \\
* & * & * & * & * & -\gamma & -\left(D W_{3}\right)^{T} \\
* & * & * & * & * & * & -\gamma
\end{array}\right]<0 \text {, }
$$

$$
\begin{aligned}
& K_{b}=W_{1} X^{-1}, \\
& K_{a}=K_{b}^{-1} W_{2}, \\
& K_{s}=K_{b}^{-1} W_{3} .
\end{aligned}
$$

The proof is given in the Appendix.

3.2.4. Improved Hybrid FTC Structure. In the traditional FTC structure, the FTC starts after the estimation process 


\section{Engine Real-Time Simulation Control Panel}

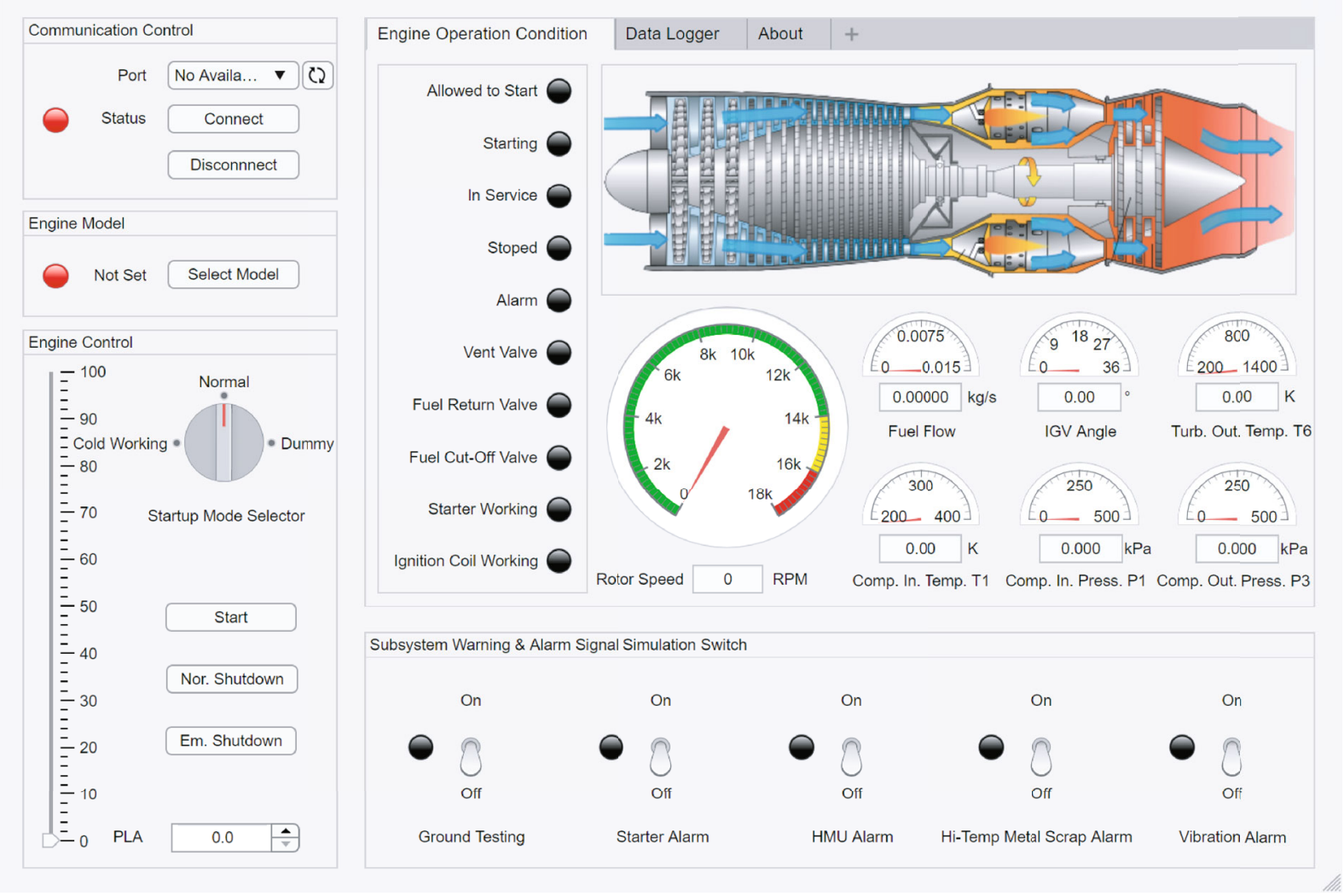

Figure 14: The interface of the host computer.

of the fault is completed; however, the influence of the fault is still in the estimation process. If the fault estimation process and FTC can be combined, the time that the closed-loop system costs can be reduced, and the influence caused by the fault can be minimized in a short time. As shown in Figure 3, the improved hybrid FTC structure proposed in this paper is based on improved HFE and FTC. An OBEM is introduced into the structure to track the aero-engine output based on the information obtained from the Kalman filter, and it is also used as the baseline model in the improved HFE process.

In this improved hybrid FTC structure, in order to reduce the influence of the fault caused by the actuator, the estimated faulty actuator information by the Kalman filter is used to adjust the control signal to the baseline control system. At the same time, the estimated sensor fault information by the Kalman filter is used to correct the value of the faulty sensor. Therefore, both the estimation and FTC processes can be merged into one process. In order to distinguish different types of faults in the system, a switching module is designed in the structure, and the switching mechanism is shown in Figure 7.

3.2.5. FDI Structure. The validation of the Kalman filter estimates is generally done by checking residuals or the differences between the measured and estimated degradation/fault output values. In our previous study [45], a weighted sum of squared residuals (WSSR) is designed to indicate the presence of a fault or degradation by

$$
\begin{gathered}
\mathrm{WSSR}_{\mathrm{HKF}}^{i}=W_{r}^{i}\left(e_{\mathrm{HKF}}^{i}\right)^{T} e_{\mathrm{HKF}}^{i}, \\
\mathrm{WSSR}_{\mathrm{OBEM}}^{i}=W_{r}^{i}\left(e_{\mathrm{OBEM}}^{i}\right)^{T} e_{\mathrm{OBEM}}^{i},
\end{gathered}
$$

where $e_{\mathrm{HKF}}^{i}=y^{i}(t)-y \wedge^{i}(t), \quad e_{\mathrm{OBEM}}^{i}=y^{i}(t)-y_{\mathrm{OBEM}}^{i}(t)$, and $y^{i}(t)$ denote the $i$ th signal (faulty signal generated by sensor or actuator) removed from the $y(t), y \wedge^{i}(t)$ is the output of the corresponding HKF, and $y_{\mathrm{OBEM}}^{i}(t)$ is the baseline output of the OBEM. The calculation structure of the WSSR for sensor location as an example is illustrated in Figure 8. The thresholds such as $\alpha$ and $\beta$ can be obtained by [26].

3.2.6. Channel Switching Mechanism and Algorithm. As discussed above, without the fault information provided by FDI, the working process of the improved hybrid FTC will not be able to start, and it leads to both the estimation and FTC processes stop running. Hence, a switching module is provided, and the structure is shown in Figure 9 The switching mechanism can be referred to [45], and the switching algorithm is shown in Figure 10. 


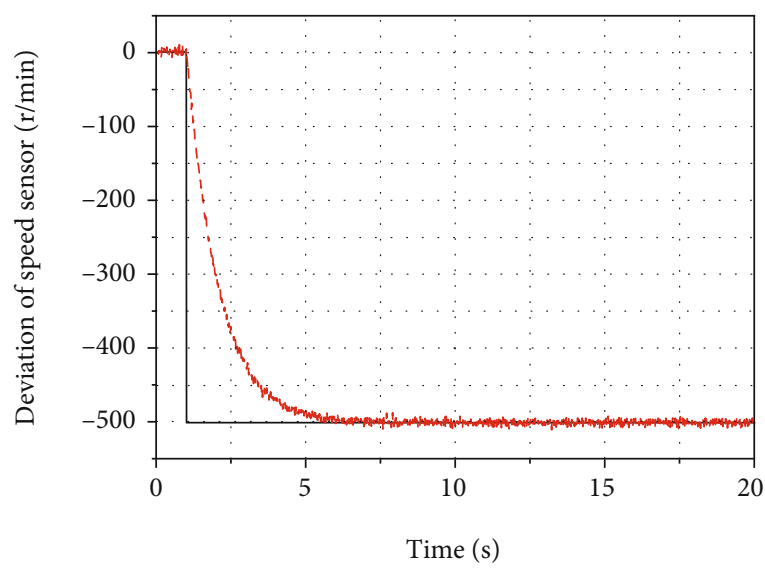

(a) Sensor fault estimation
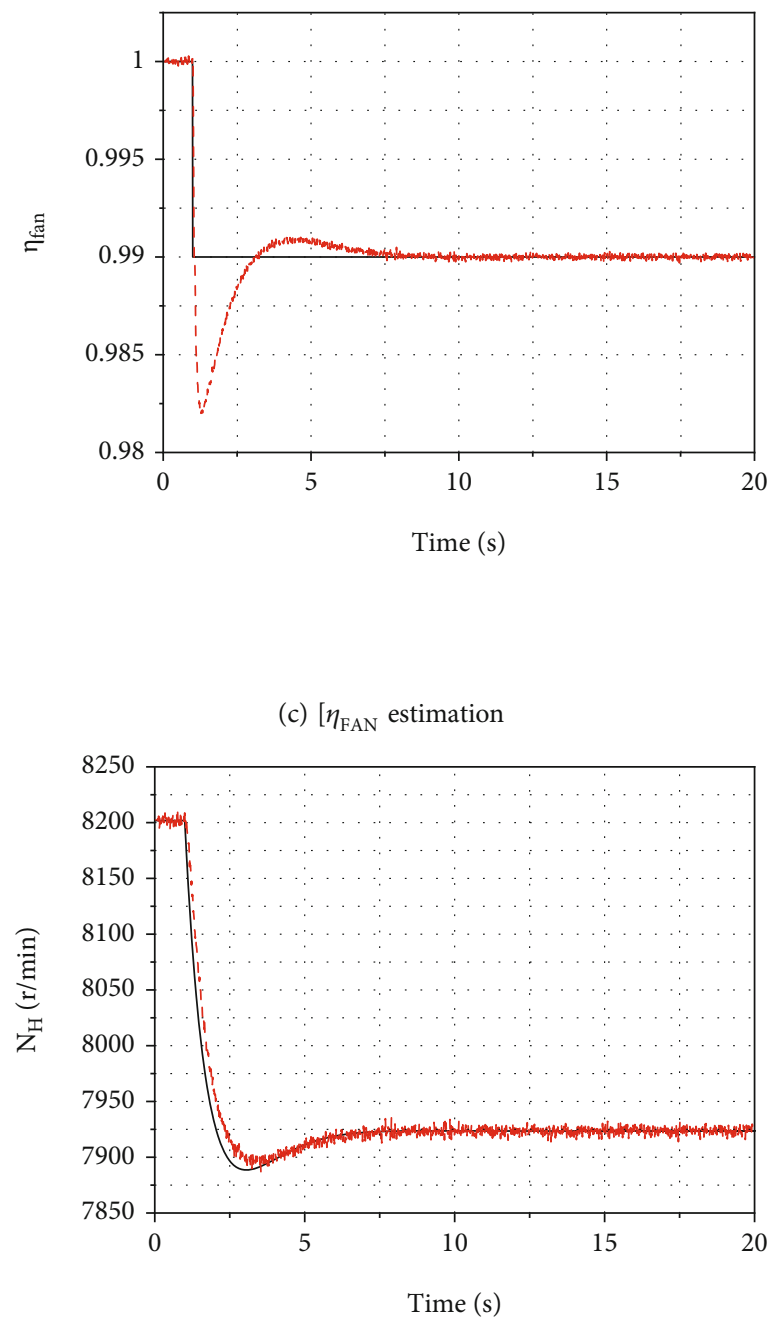

— Sensed $\mathrm{N}_{\mathrm{H}}$

-- AHFE $\mathrm{N}_{\mathrm{H}}$

(e) $N_{H}$ estimation

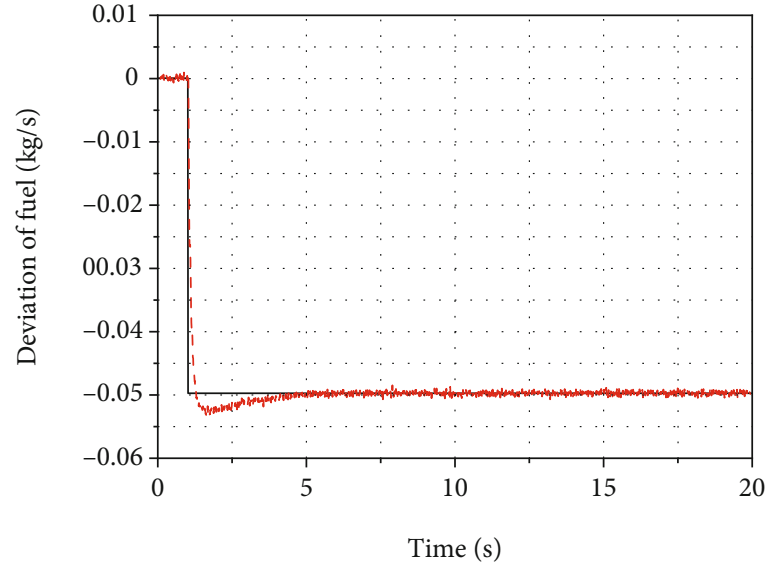

(b) Actuator estimation

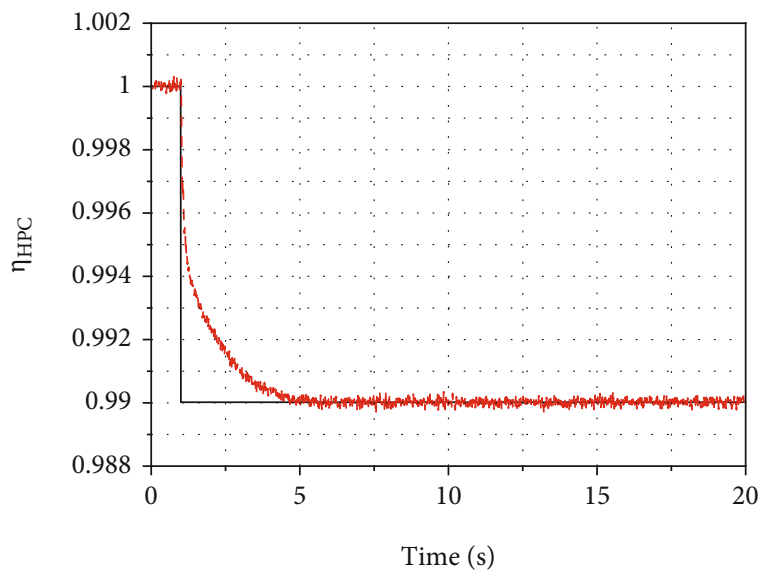

— Ref.signal

-- - AHFE

(d) $\eta_{\mathrm{HPC}}$ estimation

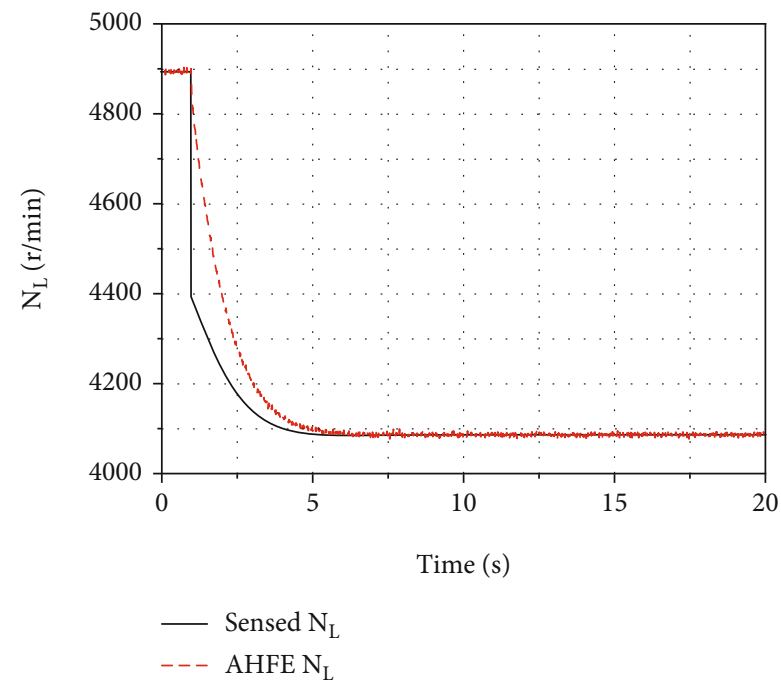

(f) $N_{L}$ estimation

FIGURE 15: Estimation result based on the improved HFE. 


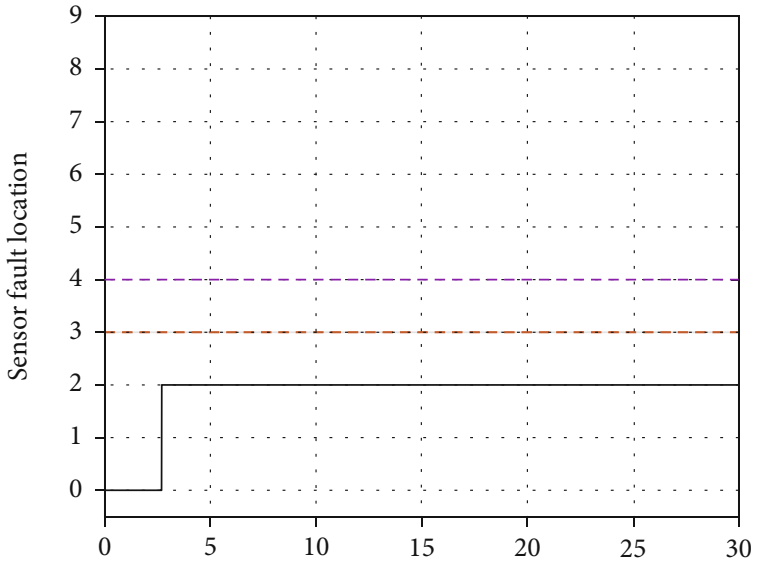

Time (s)

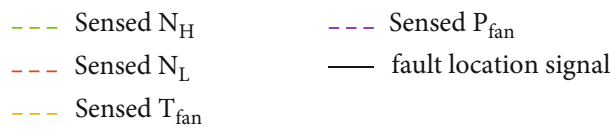

(a) Sensor fault location based on FDI

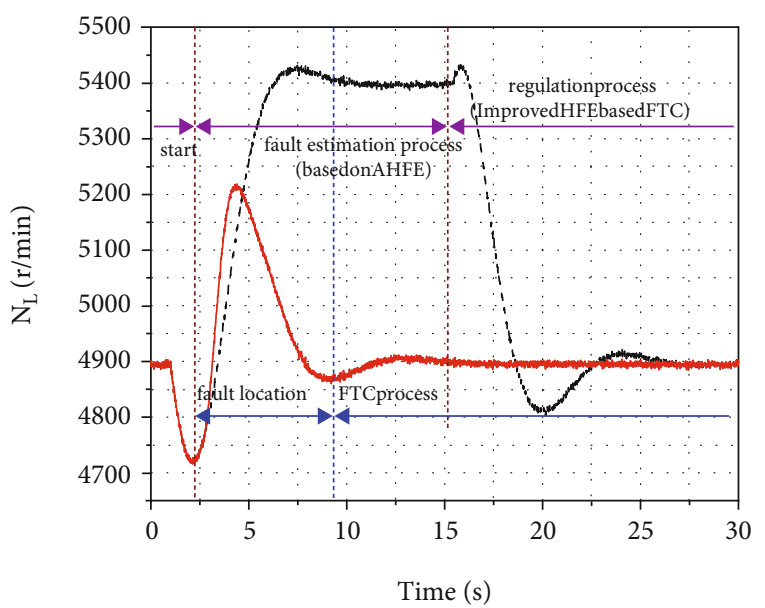

--- AHFE based FTC

— Improved hybrid FTC

(c) $N_{L}$

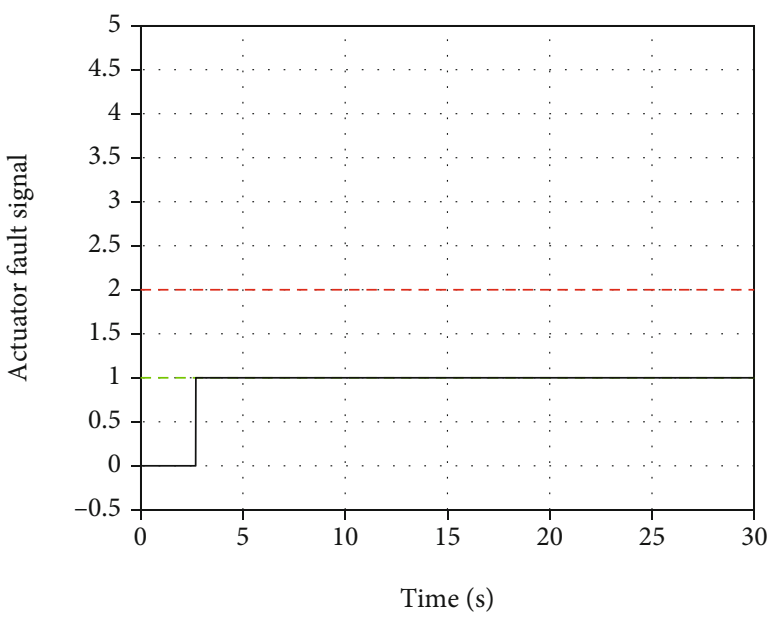

$\begin{array}{ll}\text { - - } & \text { Actuator of fuel } \\ --- & \text { Actuator of VBV } \\ \text { _ fault location signal }\end{array}$

(b) Actuator fault location based on FDI

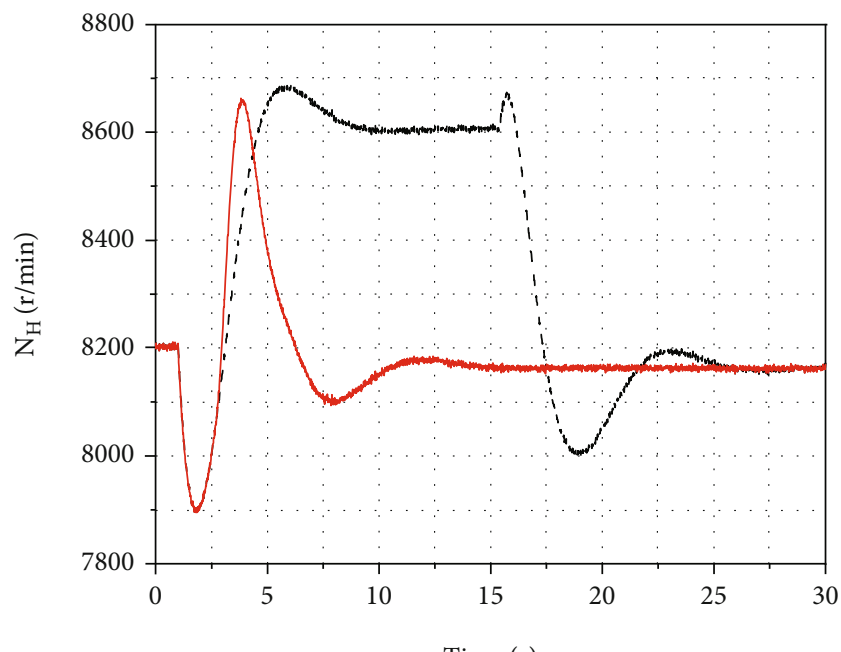

Time (s)

(d) $N_{H}$

FIgURE 16: Continued. 


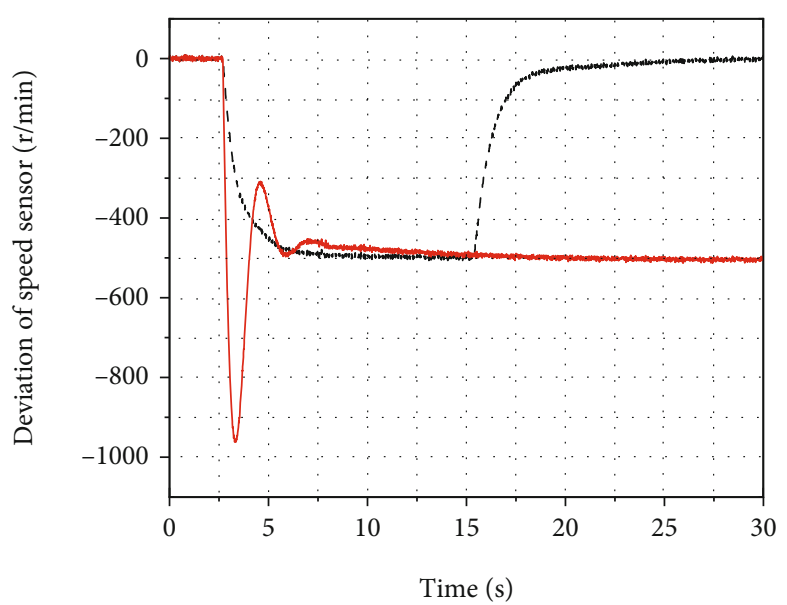

(e) Sensor fault estimation

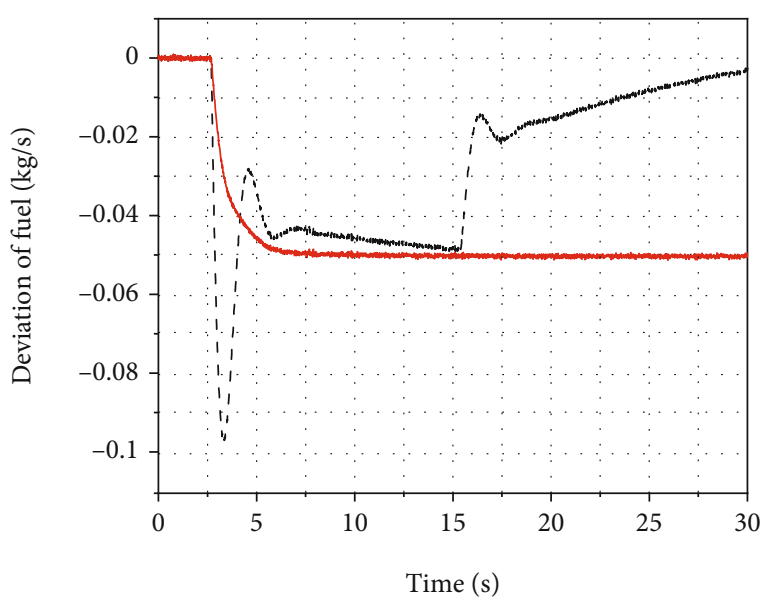

- - Improved HFE basedFTC

— Improved hybrid FTC

FIGURE 16: Comparison of experimental results between the improved hybrid FTC system and the improved HFE-based FTC system.

\section{Experimental Results and Discussion}

4.1. Experimental Setup. In order to verify the feasibility of the method proposed in this paper, a semiphysical platform for aero-engine multiple fault diagnosis and tolerant control is built up, and its structure is shown in Figure 11.

In this platform, the aero-engine is a virtual NCL model running in the simulator block, and its function is to simulate the component degradation during an experiment. Besides, the diagnosis and fault-tolerant control algorithms are also implemented in the same block. In the host computer, the control reference, e.g., power level angle (PLA), is employed, and the experimental data can also be saved and analyzed in this block. While in the hardware/physical component block, an electronic engine control (EEC) unit is installed in the platform, as shown in Figure 12, it is connected to the fuel flow regulating assembly consisting of an actuator and a fuel pump (as shown in Figure 13). In order to simplify the simulation, the VBV actuator is not used herein. One speed sensor is attached to the fuel pump and EEC unit to measure the high pressure spool speed to obtain the real engine speed according to the transmission ratio. The interface of the platform is shown in Figure 14. In this paper, the LPV form model is provided to verify the feasibility of the improved hybrid FTC algorithm, and one selected working point is shown in the Appendix.

4.2. Simulations and Experimental Results. This steady state is taken to illustrate the feasibility of the proposed method in simulation. In practice, nominal values of any steady state will be accessible via an LPV model. The experiment is implemented based on the improved HFE under the condition that the sensor fault and the actuator fault and the component parameter degradation coexist when the engine is subject to steady state. In this paper, a fault in the fuel valve opening which results in a constant deviation of fuel input is taken as an example. Sensors are set to monitor tempera- tures and pressures that are put into controllers. Errors in sensors may cause failure of the control law. Constant deviations in sensor values are taken into consideration in this section, assuming that the spool speed sensor of $N_{L}$ has a bias of $-500 \mathrm{r} / \mathrm{min}$ at $t=1 \mathrm{~s}$, which causes the input of fuel to decrease $0.05 \widehat{\mathrm{A}} \mathrm{kg} / \mathrm{s}$ and the efficiencies of the fan and the HPC 1\%. The simulation results are shown in Figure 15.

Figures 15(a) and 15(b) show the estimations of the improved HFE, Figures 15(c) and 15(d) show the component parameter degradation estimation of the improved HFE, and Figures 15(e) and 15(f) reveal the output of the improved HFE. It is found from the simulation results that the variation of faults combined with the engine component parameter degradation can be estimated based on the improved HFE. In addition, the OBEM's output can be utilized to track the engine sensor output based on the result estimated by the Kalman filter in the improved HFE.

The next experiment shows the comparison between the improved hybrid FTC system and improved HFE-based FTC system when the engine works under the steady-state condition in the semiphysical platform, and its results are shown in Figure 16. When the spool speed sensor of $N_{L}$ has the bias of $-500 \mathrm{r} / \mathrm{min}$ at $t=1 \mathrm{~s}$, the fuel input decreases $0.05 \mathrm{~kg} / \mathrm{s}$.

Figures 16(a) and 16(b) show the fault signal of the FDI, Figures 16(c) and 16(d) show comparison between the two FTC systems, and Figures 16(e) and 16(f) show the estimation results. The FTC system is based on the AHFE and consists of three parts, including the fault location process, the fault estimation process, and the FTC. While the improved hybrid FTC consists of two parts, including the fault location process and the FTC process (as shown in Figure 16(c)).

It is shown in Figures 16(a) and 16(b) that the fault location signal of the FDI generates at $t=2.7 \mathrm{~s}$, and in turn, the location of the faulty sensors and actuators are determined. Providing the fault information of the FDI, the FTC processes of the hybrid FTC system and the FTC based on the AHFE are initiated. Figures 16(c) and 16(d) show that the 
output of $N_{L}$ and $N_{H}$ of the hybrid FTC system can return to its initial state within $15 \mathrm{~s}$. Compared with the improved hybrid FTC, it takes much time to return to its initial value in the estimation process of the FTC based on the improved HFE. Figures 16(e) and 16(f) show the time difference between the improved hybrid FTC and the improved HFE in sensor and actuator fault estimation. Benefiting from the fault information transformed to the regular by estimating the variation of sensor and actuator faults, the improved hybrid FTC forces the engine output to track the OBEM output. However, in the FTC based on AHFE, this process has to be implemented after the estimation process is finished. It means that the influence of faults has been existing during the whole estimation process in the improved HFE-based FTC, and the system needs more time to complete the regulation process than the estimation process in the improved hybrid FTC.

\section{Summary and Conclusions}

In this paper, the FTC solution for simultaneous faults of actuators and sensors of an aero-engine, together with component degradation, was investigated. An improved hybrid FTC structure was proposed to keep the performance of the aero-engine closed-loop system under some harsh conditions. Some typical faults were simulated in flight envelope to provide the aero-engine component performance degradation data. By designing fault location and corresponding fault observers, the structure and design procedure of improved hybrid FTC was established. Compared with the traditional fault diagnosis and then fault-tolerant control method, the improved hybrid FTC structure proposed in this paper combined the fault estimation process and the FTC process into one process, and the influence of different faults/degradation in the aero-engine system can be reduced in a shorter time. Moreover, the simultaneous sensor and actuator faults were considered as the disturbance of the closed loop control system in the fault tolerant controller and a robust $H_{\infty}$ state feedback controller under it is designed. The switching algorithm serving for the FDI and improved hybrid FTC channels on basis of the switching scheme was provided. The semiphysical experiments were conducted to verify that the improved hybrid FTC algorithm can distinguish different types of failure in aero-engine closed-loop system and complete online fault estimation and FTC at the same time. In future research, a real-time diagnostics system used to deal with the concurrent faults in actuator and sensor will be developed.

\section{Appendix}

\section{A.1. Appendix: Proof of Theorem}

Proof. According to (49), the inequality matrix can be obtained by

$$
\left[\begin{array}{ccc}
A_{c l}^{T} P+P A_{c l} & P B_{c l} & C_{c l}^{T} \\
* & -\gamma I & D_{c l}^{T} \\
* & * & -\gamma I
\end{array}\right]<0,
$$

and substituting (47) into the above inequality matrix yields,

$$
\left[\begin{array}{ccccccc}
A^{T} P+P A+K_{b}^{T} B^{T} P+P B K_{b} & P L & P B & 0 & -P B K_{b} K_{a} & -P B K_{b} K_{s} & \left(C+D K_{b}\right)^{T} \\
* & 0 & 0 & 0 & 0 & 0 & M^{T} \\
* & * & 0 & 0 & 0 & 0 & D^{T} \\
* & * & * & 0 & 0 & 0 & V^{T} \\
* & * & * & * & -\gamma & 0 & -\left(D K_{b} K_{a}\right)^{T} \\
* & * & * & * & * & -\gamma & -\left(D K_{b} K_{s}\right)^{T} \\
* & * & * & * & * & * & -\gamma
\end{array}\right]<0 .
$$


Pre- and postumuliplying (A.2) by diag $\left(P^{-1},-I,-I,-I,-\right.$ $I,-I,-I)$ yields

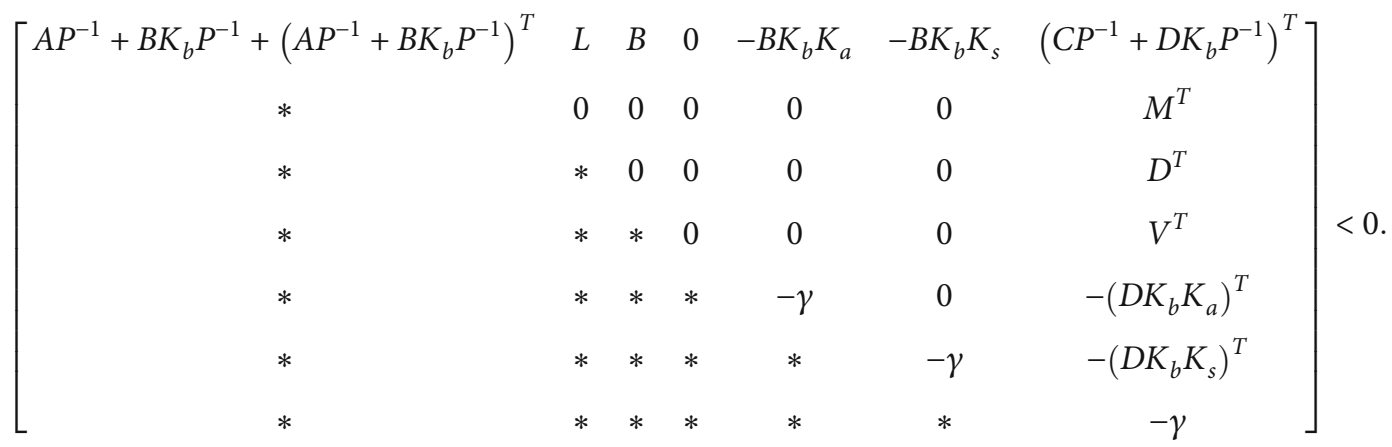

By defining $X=P^{-1}, K_{b} P^{-1}=W_{1}, K_{b} K_{a}=W_{2}, K_{b} K_{s}=$ $W_{3}$, the inequality matrix (50) can be satisfied. $\square$

\section{A.2. Data of the Aero-Engine}

In order to show the variation of engine component parameter degradation deriving from the model directly, the static state is set by $x=\left[\begin{array}{ll}8195 & 4890\end{array}\right]^{T}$ as a selected working point, and the corresponding matrices are obtained shown in (A.4).

$$
\begin{aligned}
& A=\left[\begin{array}{cc}
-1.24 & -0.90 \\
0.44 & -0.98
\end{array}\right], B=\left[\begin{array}{c}
9.43 \times 10^{-3} \\
2.87 \times 10^{-3}
\end{array}\right], C=\left[\begin{array}{cc}
1 & 0 \\
0 & 1 \\
-2.24 \times 10^{-4} & 8.78 \times 10^{-3} \\
-0.38 & 11.90 \\
-2.96 \times 10^{-2} & -8.70 \times 10^{-2} \\
3.57 & 5.99
\end{array}\right], \\
& D=\left[\begin{array}{c}
0 \\
0 \\
8.64 \times 10^{-2} \\
1.41 \times 10^{2} \\
756 \\
2.12 \times 10^{4}
\end{array}\right], L=\left[\begin{array}{cccc}
3.29 \times 10^{2} & -9.73 \times 10^{3} & -1.35 \times 10^{4} & -3.40 \times 10^{1} \\
-3.30 \times 10^{3} & 8.42 \times 10^{2} & 1.01 \times 10^{3} & -3.57 \times 10^{3}
\end{array}\right], \\
& M=\left[\begin{array}{cccc}
0 & 0 & 0 & 0 \\
0 & 0 & 0 & 0 \\
2.67 \times 10^{1} & 6.68 \times 10^{-2} & 5.77 \times 10^{-2} & 3.62 \times 10^{-2} \\
1.51 \times 10^{3} & 1.14 \times 10^{2} & 9.91 \times 10^{1} & 7.01 \times 10^{1} \\
6.65 \times 10^{1} & 2.41 \times 10^{2} & 2.68 \times 10^{2} & 2.03 \times 10^{2} \\
-2.15 \times 10^{3} & 6.20 \times 10^{3} & 7.51 \times 10^{3} & 5.90 \times 10^{3}
\end{array}\right] .
\end{aligned}
$$


And the gain matrices are shown in (A.5).

$$
K_{\text {Kal }}=\left[\begin{array}{cccccc}
K_{b}=3 \times 10^{-5}, K_{s}=1.0, K_{a}=1.33, \\
-3.7238 \times 10^{-2} & -3.7238 \times 10^{-2} & 3.6662 \times 10^{-2} & 0.3119 & -1.2464 \times 10^{-2} & -0.0114 \\
1.6066 \times 10^{-4} & 1.6066 \times 10^{-4} & -1.0028 \times 10^{-4} & -1.7107 \times 10^{-4} & 1.7806 \times 10^{-4} & -4.9549 \times 10^{-5} \\
-2.2022 \times 10^{-4} & -2.2022 \times 10^{-4} & -3.2553 \times 10^{-5} & 6.0134 \times 10^{-6} & 1.3515 \times 10^{-4} & 1.7911 \times 10^{-4} \\
1.4089 \times 10^{-4} & 1.4089 \times 10^{-4} & 3.3513 \times 10^{-5} & 8.2847 \times 10^{-5} & -9.7390 \times 10^{-5} & -2.5028 \times 10^{-4} \\
-7.0949 \times 10^{-5} & -7.0949 \times 10^{-5} & 4.6983 \times 10^{-5} & -2.5119 \times 10^{-4} & -1.6219 \times 10^{-4} & -5.3121 \times 10^{-5}
\end{array}\right],
$$

\section{Data Availability}

All data, models, and code generated or used during the study appear in the submitted article.

\section{Conflicts of Interest}

The authors declare that they have no conflicts of interest.

\section{Acknowledgments}

This work was supported by the Major Project of National Natural Science Foundation of China (Nos. 61890921 and 61890923) and National Science and Technology Major Project (No. 2017-I-0001-0001).

\section{References}

[1] H. Noura, D. Theilliol, J.-C. Ponsart, and A. Chamseddine, Fault-Tolerant Control Systems: Design and Practical Applications, Springer Science \& Business Media, 2009.

[2] Y. Yuan, X. Liu, S. Ding, and B. Pan, "Fault detection and location system for diagnosis of multiple faults in aeroengines," IEEE Access, vol. 5, pp. 17671-17677, 2017.

[3] P. G. León, J. García-Morales, R. F. Escobar-Jiménez, J. F. Gómez-Aguilar, G. López-López, and L. Torres, "Implementation of a fault tolerant system for the internal combustion engine's MAF sensor," Measurement, vol. 122, pp. 91-99, 2018.

[4] T. Kobayashi and D. L. Simon, "Aircraft engine sensor/actuator/component fault diagnosis using a bank of Kalman filters," NASA Tech. Rep. NASA/CR-2003-212298, Glenn Research Center, Cleveland, OH, USA, 2003.

[5] J. Chen, R. J. Patton, and G.-P. Liu, "Optimal residual design for fault diagnosis using multi-objective optimization and genetic algorithms," International Journal of Systems Science, vol. 27, no. 6, pp. 567-576, 1996.

[6] H. Wang and S. Daley, "Actuator fault diagnosis: an adaptive observer-based technique," IEEE transactions on Automatic Control, vol. 41, no. 7, pp. 1073-1078, 1996.

[7] K. K. Botros, G. Kibrya, and A. Glover, "A demonstration of artificial neural-networks-based data mining for gas-turbinedriven compressor stations," Journal of Engineering for Gas Turbines and Power, vol. 124, no. 2, pp. 284-297, 2002.

[8] R. Marcello, "Kalman filters and neural-network schemes for sensor validation in flight control systems," IEEE Transactions on Control Systems Technology, vol. 6, no. 5, pp. 596-611, 1998.

[9] M. Sami and R. J. Patton, "Active fault tolerant control for nonlinear systems with simultaneous actuator and sensor faults," International Journal of Control, Automation and Systems, vol. 11, no. 6, pp. 1149-1161, 2013.

[10] F. Shi and R. J. Patton, "Fault estimation and active fault tolerant control for linear parameter varying descriptor systems," International Journal of Robust and Nonlinear Control, vol. 25, no. 5, pp. 689-706, 2015.

[11] M. Rodrigues, H. Hamdi, N. B. Braiek, and D. Theilliol, "Observer-based fault tolerant control design for a class of lpv descriptor systems," Journal of the Franklin Institute, vol. 351, no. 6, pp. 3104-3125, 2014.

[12] J. Cieslak, D. Henry, A. Zolghadri, and P. Goupil, "Development of an active fault-tolerant flight control strategy," Journal of guidance, control, and dynamics, vol. 31, no. 1, pp. 135-147, 2008.

[13] P. Shi, M. Liu, and L. Zhang, "Fault-tolerant sliding-modeobserver synthesis of Markovian jump systems using quantized measurements," IEEE Transactions on Industrial Electronics, vol. 62, no. 9, pp. 5910-5918, 2015.

[14] J. Lan and R. J. Patton, "A new strategy for integration of fault estimation within fault-tolerant control," Automatica, vol. 69, pp. $48-59,2016$. 
[15] J. Cieslak, D. Gucik-Derigny, and J. Chang, "Hybrid healthaware supervisory control framework with a prognostic decision-making," in In Advances in Diagnostics of Processes and Systems, pp. 3-16, Springer, 2021.

[16] D. Efimov, J. Cieslak, and D. Henry, "Supervisory faulttolerant control with mutual performance optimization," International Journal of Adaptive Control and Signal Processing, vol. 27, no. 4, pp. 251-279, 2013.

[17] M. Blanke, M. Kinnaert, J. Lunze, M. Staroswiecki, and J. Schröder, Diagnosis and Fault-Tolerant Control, Volume 2, Springer, 2006.

[18] J. Jiang, "Fault-tolerant control systems-an introductory overview," Acta Automatica Sinica, vol. 31, no. 1, pp. 161-174, 2005.

[19] Y. Zhang and J. Jiang, "Bibliographical review on reconfigurable fault-tolerant control systems," Annual Reviews in Control, vol. 32, no. 2, pp. 229-252, 2008.

[20] C. Sloth, T. Esbensen, and J. Stoustrup, "Robust and faulttolerant linear parameter-varying control of wind turbines," Mechatronics, vol. 21, no. 4, pp. 645-659, 2011.

[21] J. Jiang and X. Yu, "Fault-tolerant control systems: a comparative study between active and passive approaches," Annual Reviews in Control, vol. 36, no. 1, pp. 60-72, 2012.

[22] S. Garg, "Controls and health management technologies for intelligent aerospace propulsion systems," in In 42nd AIAA Aerospace Sciences Meeting and Exhibit, Reno, Nevada, 2004.

[23] J. S. Litt, D. L. Simon, S. Garg et al., "A survey of intelligent control and health management technologies for aircraft propulsion systems," Journal of aerospace computing, information, and Communication, vol. 1, no. 12, pp. 543-563, 2004.

[24] A. Behbahani, S. Adibhatla, and C. Rauche, "Integrated modelbased controls and phm for improving turbine engine performance, reliability, and cost," in In 45th AIAA/ASME/SAE/ASEE Joint Propulsion Conference \& Exhibit, Denver, Colorado, 2009.

[25] T. Kobayashi and D. L. Simon, "Hybrid Kalman filter approach for aircraft engine in-flight diagnostics: sensor fault detection case," in Volume 2: Aircraft Engine; Ceramics; Coal, Biomass and Alternative Fuels; Controls, Diagnostics and Instrumentation; Environmental and Regulatory Affairs, Barcelona, Spain, 2006.

[26] T. Kobayashi and D. L. Simon, "Hybrid kalman filter approach for aircraft engine in-flight diagnostics: sensor fault detection case," In Turbo Expo: Power for Land, Sea, and Air, vol. 42371, pp. 745-755, 2006.

[27] S. Garg, "Propulsion controls and diagnostics research at NASA Glenn," in 43rd AIAA/ASME/SAE/ASEE Joint Propulsion Conference \& Exhibit, Cincinnati, OH, 2007.

[28] D. L. Simon and S. Garg, "Optimal tuner selection for Kalman filter-based aircraft engine performance estimation," Journal of Engineering for Gas Turbines and Power, vol. 132, no. 3, 2010.

[29] B. Pourbabaee, N. Meskin, and K. Khorasani, "Multiple-model based sensor fault diagnosis using hybrid Kalman filter approach for nonlinear gas turbine engines," in In 2013 American control conference, pp. 4717-4723, Washington, DC, USA, 2013.

[30] D. L. Simon and J. B. Armstrong, "An integrated approach for aircraft engine performance estimation and fault diagnostics," Journal of engineering for gas turbines and power, vol. 135, no. 7, 2013.
[31] A. W. Rinehart and D. L. Simon, "An integrated architecture for aircraft engine performance monitoring and fault diagnostics: engine test results," in 50th AIAA/ASME/SAE/ASEE Joint Propulsion Conference, OH, 2014.

[32] X. Liu, J. Zhu, C. Luo, L. Xiong, and Q. Pan, "Aero-engine health degradation estimation based on an underdetermined extended Kalman filter and convergence proof," ISA Transactions, 2021.

[33] A. Volponi and D. L. Simon, "Enhanced self tuning on-board real-time model (eSTORM) for aircraft engine performance health tracking," Journal of engineering for gas turbines and power, 2008.

[34] A. Volponi, T. Brotherton, and R. Luppold, "Empirical tuning of an on-board gas turbine engine model for real-time module performance estimation," Journal of engineering for gas turbines and power, vol. 130, no. 2, 2008.

[35] X. Liu, N. Xue, and Y. Yuan, "Aircraft engine sensor fault diagnostics using an on-line obem update method," PloS one, vol. 12, no. 2, article e0171037, 2017.

[36] S. Ding, Y. Yuan, N. Xue, and X. Liu, "An onboard aeroengine model-tuning system," Journal of Aerospace Engineering, vol. 30, no. 4, article 04017018, 2017.

[37] S. Ding, Y. Yuan, N. Xue, and X. Liu, "Online fault-tolerant onboard aeroengine model tuning structure," International Journal of Aerospace Engineering, vol. 2016, 15 pages, 2016.

[38] X. Liu, L. Xiong, and C. Luo, "An adaptive hybrid faulttolerant control system design for aeroengine sensor and actuator faults," in Proceedings of the 2020 2nd International Conference on Robotics, Intelligent Control and Artificial Intelligence, Shanghai, China, 2020.

[39] L. C. Jaw and J. D. Mattingly, Aircraft Engine Controls, AIAA, Reston, VA, 2009.

[40] E. Mohammadi and M. Montazeri-Gh, "Active fault tolerant control with self-enrichment capability for gas turbine engines," Aerospace Science and Technology, vol. 56, pp. 70-89, 2016.

[41] E. Mohammadi and M. Montazeri-Gh, "Performance enhancement of global optimization-based gas turbine fault diagnosis systems," Journal of Propulsion and Power, vol. 32, no. 1, pp. 214-224, 2016.

[42] R. Tóth, Modeling and Identification of Linear ParameterVarying Systems, Volume 403, Springer, 2010.

[43] G. Dukeman, "Profile-following entry guidance using linear quadratic regulator theory," in In AIAA guidance, navigation, and control conference and exhibit, Monterey California, USA, 2002.

[44] M. Vidyasagar, Nonlinear Systems Analysis, SIAM, 2002.

[45] Y. Yuan, S. Ding, X. Liu, and Q. Pan, "Hybrid diagnosis system for aeroengine sensor and actuator faults," Journal of Aerospace Engineering, vol. 33, no. 1, article 04019108, 2020. 